\title{
Upper-Extremity Postures and Activities in Naturalistic Driving
}

\author{
Final Report \\ UMTRI-2016-20 \\ Matthew P. Reed \\ Sheila M. Ebert \\ Biosciences Group \\ University of Michigan Transportation Research Institute
}

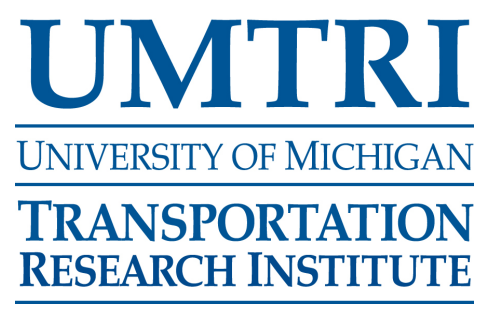


Upper-Extremity Postures and Activities in Naturalistic Driving

Final Report

UMTRI-2016-20

by

Matthew P. Reed

Sheila M. Ebert

University of Michigan Transportation Research Institute

September 2016 


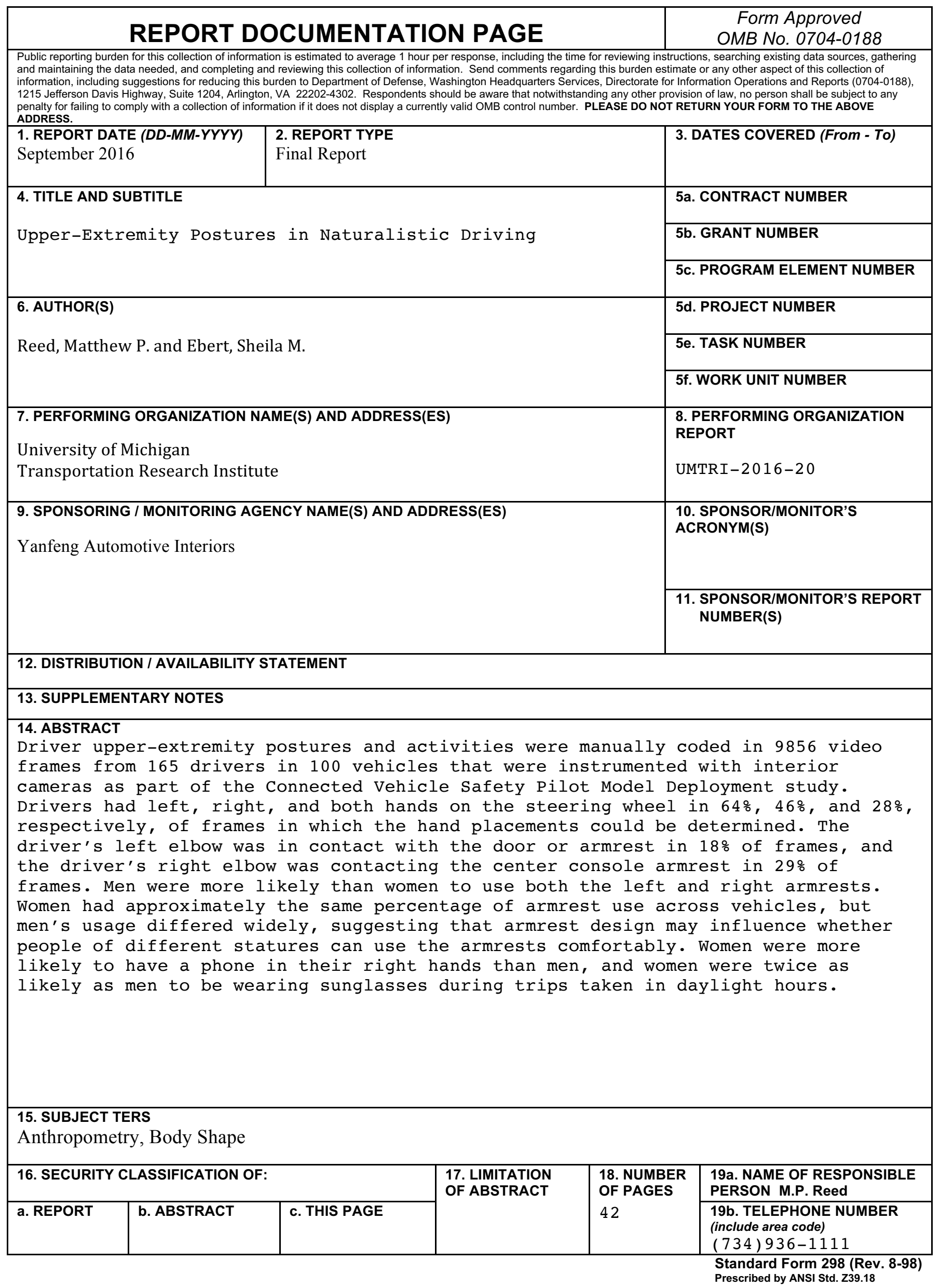




\section{ACKNOWLEDGMENTS}

This research was supported by Yanfeng Automotive Interiors. We acknowledge the invaluable support and collaboration Beth McGough of Yanfeng. The data used for this study were gathered in the Connected Vehicle Safety Pilot Model Deployment study, funded by the U.S. Department of Transportation, ITS Joint Program Office, and led by our UMTRI colleague Dr. Jim Sayer. We acknowledge the invaluable contribution of Bob Goodsell, who created the data analysis tool. We also acknowledge Gavin Amezaga, Bansili Desai, Riley Horn, and Jamie Morrison, who assisted in the development the software tool and for coded the videos. 
CONTENTS

ABSTRACT

INTRODUCTION

$\begin{array}{lr}\text { METHODS } & 8\end{array}$

$\begin{array}{ll}\text { RESULTS } & 25\end{array}$

$\begin{array}{lr}\text { DISCUSSION } & 29\end{array}$

$\begin{array}{ll}\text { REFERENCES } & 30\end{array}$

$\begin{array}{ll}\text { APPENDIX } & 31\end{array}$ 


\begin{abstract}
Driver upper-extremity postures and activities were manually coded in 9856 video frames from 165 drivers in 100 vehicles that were instrumented with interior cameras as part of the Connected Vehicle Safety Pilot Model Deployment study. Drivers had left, right, and both hands on the steering wheel in $64 \%, 46 \%$, and $28 \%$, respectively, of frames in which the hand placements could be determined. The driver's left elbow was in contact with the door or armrest in $18 \%$ of frames, and the driver's right elbow was contacting the center console armrest in $29 \%$ of frames. Men were more likely than women to use both the left and right armrests. Women had approximately the same percentage of armrest use across vehicles, but men's usage differed widely, suggesting that armrest design may influence whether people of different statures can use the armrests comfortably. Women were more likely to have a phone in their right hands than men, and women were twice as likely as men to be wearing sunglasses during trips taken in daylight hours.
\end{abstract}




\section{INTRODUCTION}

Naturalistic driving studies (NDS) deploy instrumented vehicles to study many facets of the driving process. The University of Michigan Transportation Research Institute (UMTRI) has conducted many NDS over the past 20 years, studying advanced driver assistance systems and many facets of driving performance. The Connected Vechicle Safety Pilot Model Deployment (SPMD) study was focused on testing vehicle-to-vehicle and vehicle-to-infrastructure communication technologies (Bezzina and Sayer 2015). As part of that study, 100 drivers who owned small sedans were recruited to have their vehicles instrumented. The vehicles were equipped with sensors to record a wide range of vehicle performance data. Cameras were mounted on the vehicle to record the exterior scene, and one camera was mounted near the inside mirror to record the driver's activities.

The driver video provides a rich opportunity to quantify many aspects of driver behavior. The current analysis is focused on upper extremity activities, with a particular focus on resting postures. Video frames were sampled from a selection of trips with each equipped vehicle. A coding methodology was developed to categorize the upper extremity postures and activities, along with a few other aspects of driver behavior. The data were summarized to identify the distribution of behaviors as a function of driver and trip attributes. 


\section{METHODS}

\section{Database}

The SPMD database contains a large amount of data that can be accessed by queries indexed by vehicle, trip, and many other variables. Figure 1 shows a sample video frame, demonstrating the typical view of the driver. The records span weeks of driving and dozens of trips for each vehicle. UMTRI has developed specialized software for viewing and analyzing naturalistic driving data, including video. In this study, this software was used to sample from within this large dataset and to manually code patterns of armrest usage from the video data.

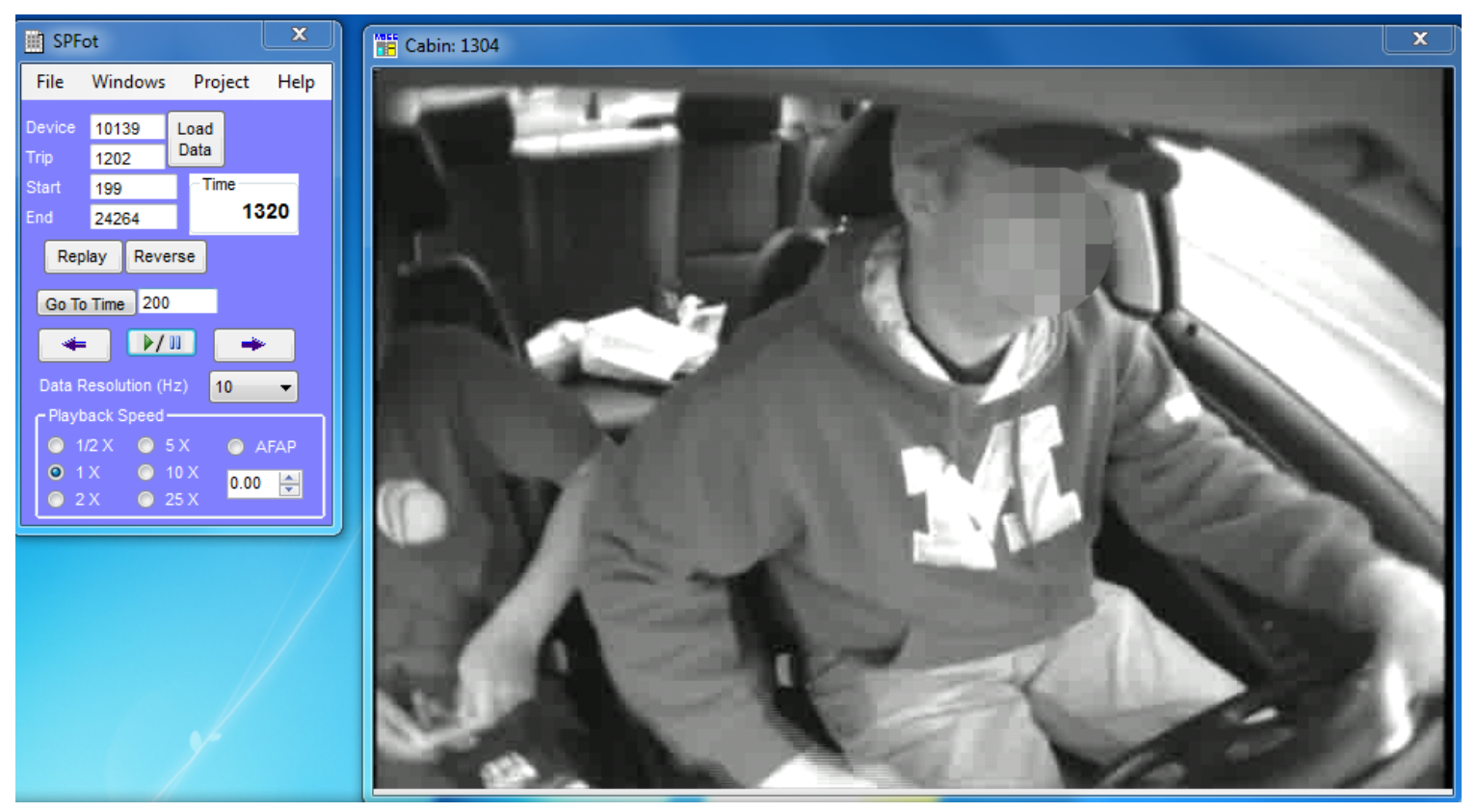

Figure 1. Example of camera view from SPMD and software interface for viewing cabin videos

\section{Vehicles}

One hundred vehicles were included in this study. All were passenger sedans from GM, Ford, and Honda. The vehicles included are listed in Table 1 and Figure 2 shows examples of interiors from vehicles of the same make, model and model year. 
Table 1

Study Vehicles

\begin{tabular}{lllc}
\hline Make & Model & Year & Count \\
\hline Chevrolet & Impala & 2007 & 2 \\
Chevrolet & Impala & 2008 & 2 \\
Chevrolet & Impala & 2010 & 2 \\
Chevrolet & Malibu & 2009 & 4 \\
Chevrolet & Malibu & 2010 & 2 \\
Chevrolet & Malibu & 2011 & 2 \\
Chevrolet & Malibu & 2012 & 4 \\
Chevy & Malibu & 2008 & 2 \\
Ford & Focus & 2012 & 3 \\
Ford & Focus & 2013 & 1 \\
Ford & Fusion & 2010 & 18 \\
Ford & Fusion & 2011 & 3 \\
Ford & Fusion & 2012 & 4 \\
Honda & Civic & 2006 & 8 \\
Honda & Civic & 2007 & 3 \\
Honda & Civic & 2008 & 9 \\
Honda & Civic & 2009 & 7 \\
Honda & Civic & 2010 & 4 \\
Honda & Civic & 2011 & 1 \\
Pontiac & G6 & 2006 & 1 \\
Pontiac & G6 & 2007 & 1 \\
Pontiac & G6 & 2008 & 2 \\
Pontiac & G6 & 2009 & 3 \\
Saturn & Aura & 2007 & 3 \\
Saturn & Aura & 2008 & 5 \\
Saturn & Aura & 2009 & 2 \\
Saturn & Aura & 2010 & 1 \\
\hline & & &
\end{tabular}




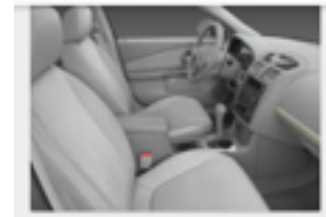

4 2006_chevrolet_malibu.

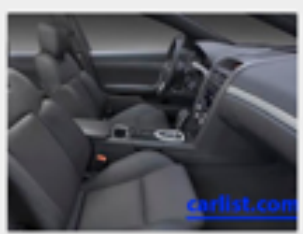

ㄴ 2009_pontiac_g6_int.jp.

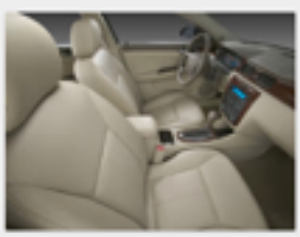

4. 2012-Chevrolet-Impala

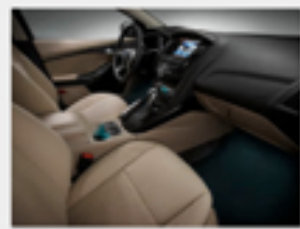

ㄴ 2012-Ford-Focus-EV-ln.

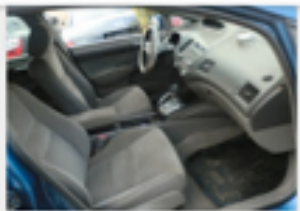

4 2006-2011 Honda Civi.

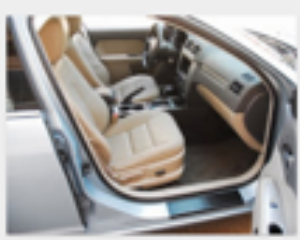

4. 2010 FordFusionhtybrid.

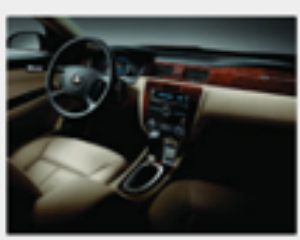

E 2012-Cheny-Impala-Int.

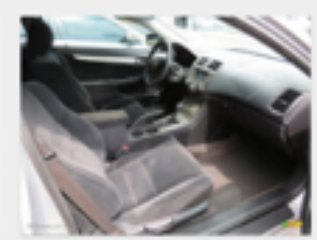

A Honda Accord 2006.jp.

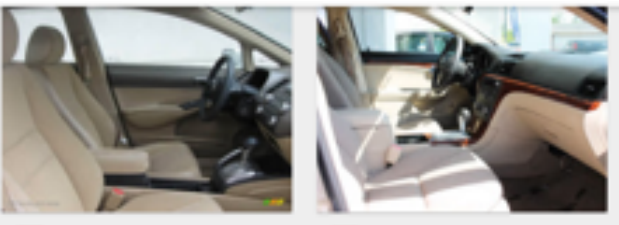

4. 2006-2011 Honda Cin. 2007 -satum-aura-ballwe

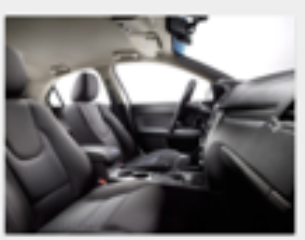

ㄷ 2012 Ford Fusion.png

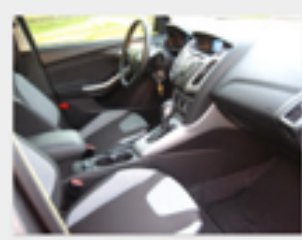

- 2012 ford_focus_se h...

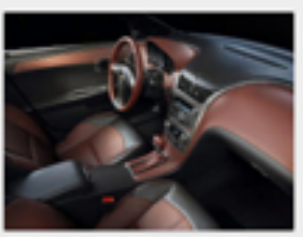

4. 2012 Chevy-Malibu-int.

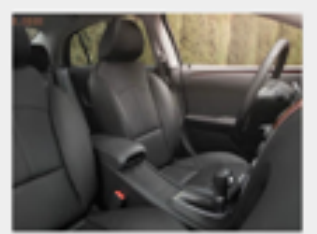

A 2012-Cheny-Malibu-int.

Figure 2. Examples of vehicle interiors (not necessarily representative of tested vehicles).

\section{Data Acquisition System}

In addition to collecting video data of the cabin, the data acquisition system in the vehicles recorded the information in Table 2 at $10 \mathrm{~Hz}$. The vehicle's GPS position, speed, and heading were recorded as defined by the SAE J2735 standard (Bezzina \& Sayer 2015). 
Table 2

Participant information

\begin{tabular}{|c|c|c|}
\hline $\begin{array}{l}\text { DAS } \\
\text { Input }\end{array}$ & Description & Units \\
\hline Data Time & Time in centiseconds since DAS started & $\operatorname{csec}$ \\
\hline Accel Pedal & Accelerator pedal & $\%$ \\
\hline Altitude & Height above the ellipsoid & $\mathrm{m}$ \\
\hline Available Left & Mobil Eye left LDW availability & none \\
\hline Available Right & Mobileye right LDW availability & none \\
\hline $\mathrm{X}$-axis & Longitudinal acceleration from Conti IMU & $\mathrm{m} / \mathrm{sec} 2$ \\
\hline Y-axis & Lateral acceleration from Conti IMU & $\mathrm{m} / \mathrm{sec} 2$ \\
\hline Boundary Left & Mobil Eye left lane type & none \\
\hline Boundary Right & Mobil Eye right lane type & none \\
\hline Brake & Brake light active & none \\
\hline Cruise Engaged & Cruise control active & none \\
\hline Distance & Trip distance & $\mathrm{m}$ \\
\hline GPS Heading & GPS heading from Ublox GPS & degrees \\
\hline Latitude & Latitude from Ublox GPS & degrees \\
\hline Longitude & Longitude from Ublox GPS & degrees \\
\hline Num Targets & Mobileye number of obstacles & none \\
\hline Range & $\begin{array}{l}\text { Mobileye Object } 1 \text { longitudinal position relative to the } \\
\text { reference point. }\end{array}$ & $\mathrm{m}$ \\
\hline Range Rate & Mobil Eye relative longitudinal velocity of object1 & $\mathrm{m} / \mathrm{sec}$ \\
\hline Turn Signal & Turn signal & none \\
\hline Yaw Rate & Yaw rate from Conti IMU & $\begin{array}{l}\text { degrees } \\
\text { /second }\end{array}$ \\
\hline Speed & Vehicle speed from transmission & $\mathrm{m} / \mathrm{sec}$ \\
\hline TOD Trip Start & $\begin{array}{l}\text { Absolute date/time corresponding to test time }=0 \text { in access } \\
\text { date/time format based on computer clock }\end{array}$ & none \\
\hline Odometer & Odometer & $\mathrm{m}$ \\
\hline Local Time & GPS milliseconds in week from GPS & msec \\
\hline
\end{tabular}

\section{Participants}

The SPDM did not require the vehicle to be driven solely by the owner of the vehicle. Therefore, half the vehicles sampled had more than one driver, with twelve vehicles having three drivers, two vehicles having four drivers, and one having five drivers. A total of 165 drivers were observed ( 96 women and 69 men). Screen shot of each individual driver was taken (Figure 3 ) and stored with an assigned driver number. For each trip coded, the reviewers checked the photos to determine and record which driver was present in the video.

Front seat passengers were present in $18 \%$ of the frames coded. However, in some vehicles only the left side of the passenger's body was visible; gender and age were impossible to determine in most of those cases, a total of about $10 \%$ of passenger observations. Of the other frames, $60 \%$ of the front seat passengers were women and the remainder men.

The SPDM did not regularly record participant age, stature or weight. Therefore, the age and build of participants was estimated from video. Due to the imprecision of this method, age was grouped into three categories: less than 30 years, between 30 and 60 years and over 60 years. Tables 3 and 4 list the age distribution of the 
drivers and passengers in the frames coded. Participant weight relative to stature was categorized as lean, heavy or obese, which would roughly correspond to a body mass inex $\left(\mathrm{kg} / \mathrm{m}^{2}\right)$ of $<25,25$ to 30 and $>30$ respectively. Of the frames coded, the driver was categorized as lean in $65 \%$, overweight in $30 \%$ and obese in $5 \%$. This level of obesity is much lower than the population as a whole (approximately $30 \%$ of US adults are obese), so these values are likely to be skewed low. Of the frames with a front passenger present, the passengers were categorized as $67 \%$ lean, $24 \%$ overweight, and $2 \%$ obese.

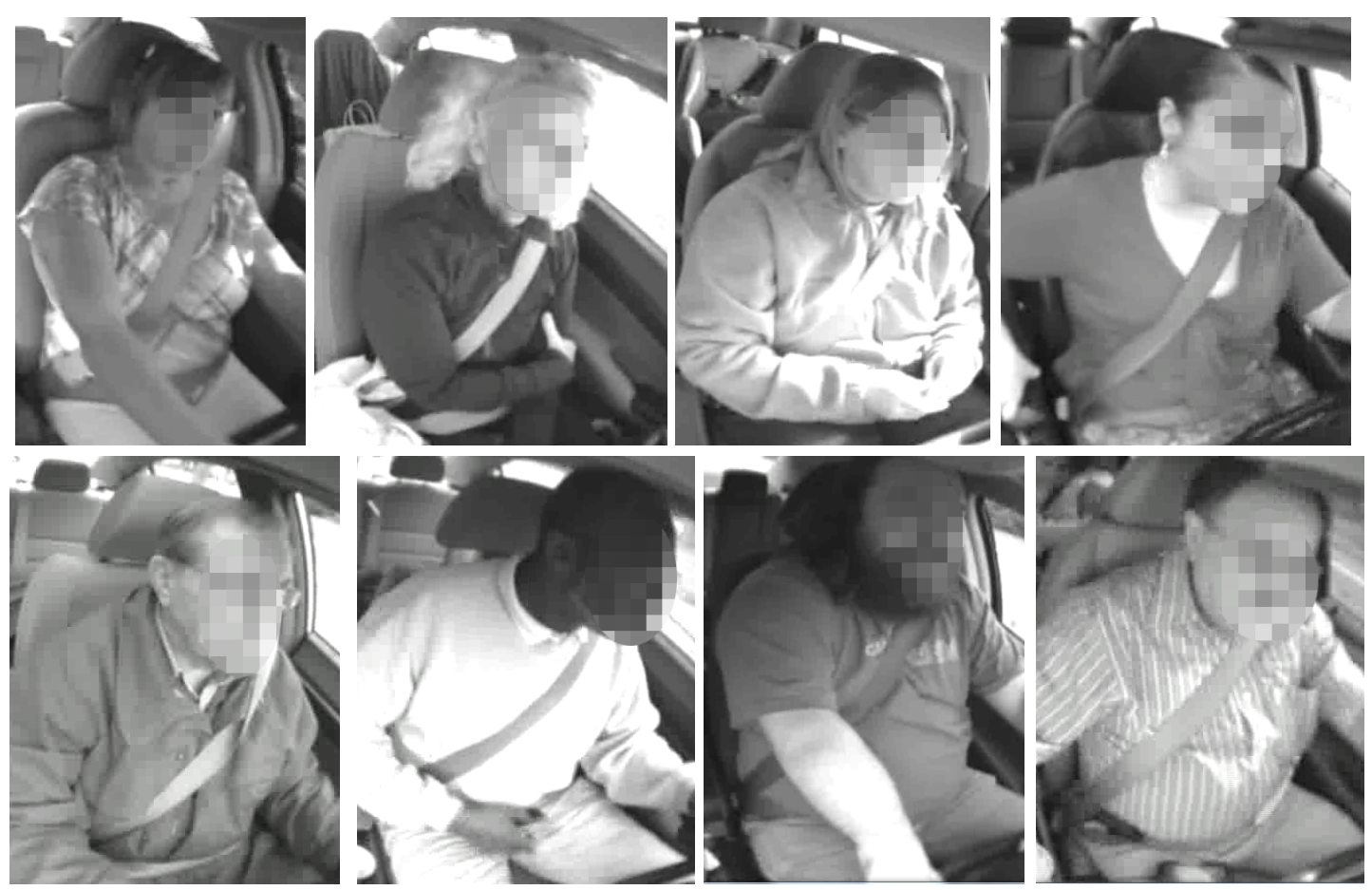

Figure 3. Examples of diver screenshots used to determine which participant was driving

Table 3

Driver Age Distribution

\begin{tabular}{ccc}
\hline $\begin{array}{c}\text { Age Category } \\
\text { (years) }\end{array}$ & Number of Drivers & $\begin{array}{c}\text { Percentage of Coded } \\
\text { Trips (\%) }\end{array}$ \\
\hline$<30$ & 51 & 31 \\
$30-60$ & 106 & 65 \\
$>60$ & 7 & 4 \\
\hline
\end{tabular}


Table 4

Passenger Age Distribution

\begin{tabular}{cc}
\hline Age Category (years) & $\begin{array}{c}\text { Percentage of Coded } \\
\text { Trips (\%) }\end{array}$ \\
\hline$<30$ & 30 \\
$30-60$ & 46 \\
$>60$ & 16 \\
Unable to Categorize & 8 \\
\hline
\end{tabular}

\section{Customized Video Coding Tool}

Figure 4 shows a screenshot of the coding tool developed for this study. Radio buttons allowed only one response per question, and check boxes allowed multiple responses. The details of the coding tool interface are described below.

\section{Driver and Passenger Physical Characteristics and Torso Orientation}

Figure 5 and 6 show the areas of the coding tool where investigators recorded information characterizing torso orientation and physical characteristics the driver and front passenger. Torso orientation was referred to as "Torso Lean" to the right, left, forward or none. Examples of the postures are in Figure 7. Physical characteristics included gender (male, female or unknown in the case of some passengers), weight category (lean, heavy, obese), age ( $<30$ years, 30-60 years, and $>60$ years), whether the driver was wearing sunglasses (yes or no) and hair color (dark or light) to help distinguish between different drivers and passengers within a car.

\section{Driver Upper Limb Location with Detailed Information on Armrest Usage}

Figure 8 and Tables 5 and 6 detail how the location and possible interactions of the elbow, forearm and hands of the driver and front passenger were recorded the coding tool. The locations where the occupants touched the armrest was divided into three areas show in Figure 9, front, top and side. The zones of possible limb contact with the rest of the body are shown in Figure 10, and the elbow, forearm and hand was divided as shown in Figure 11. Figures 12-19 show examples of limb positions and object interactions. 


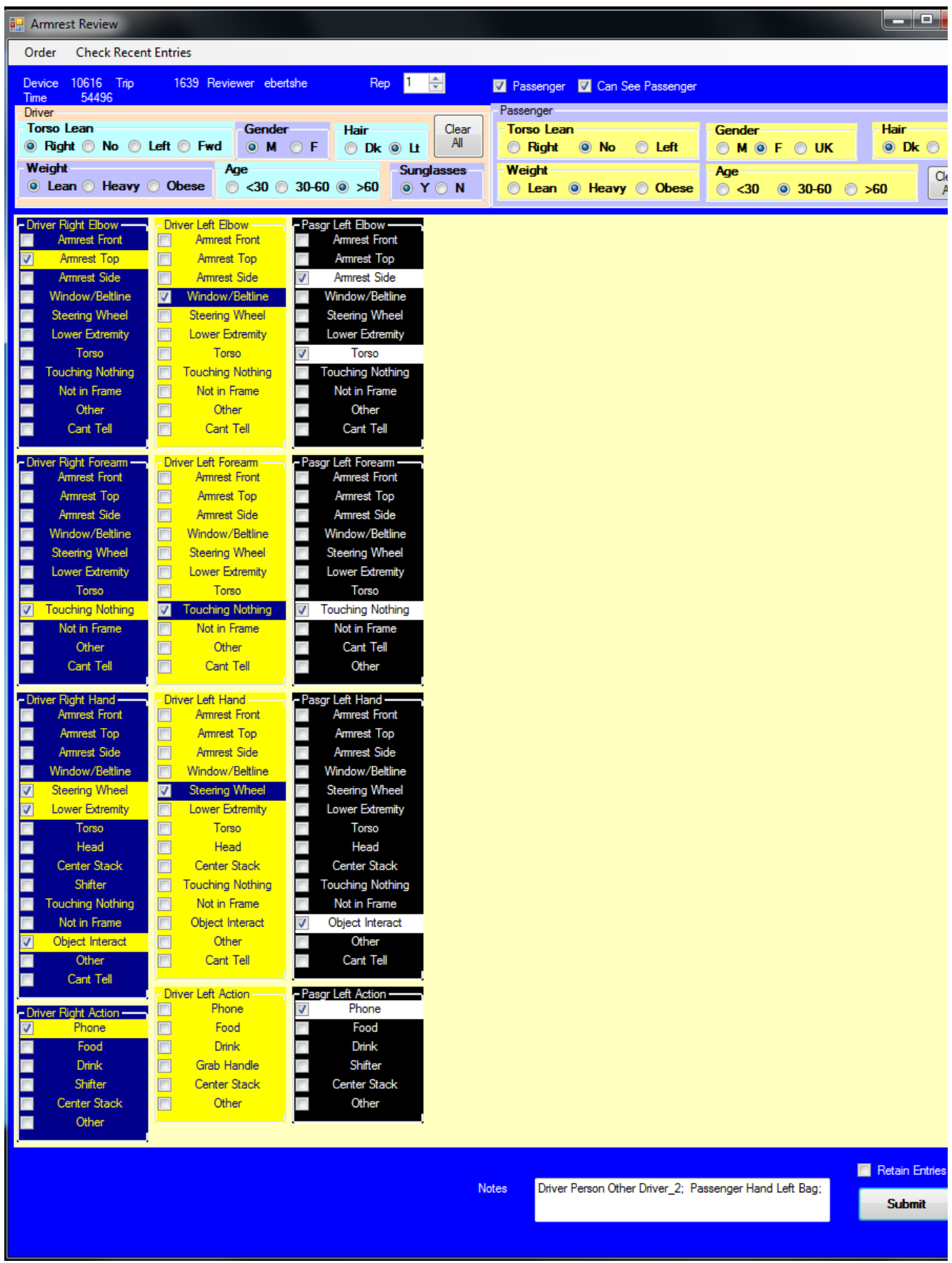

Figure 4. Example observations recorded on the customized video coding tool 


\begin{tabular}{|c|c|c|c|c|c|}
\hline \\
\hline \multirow{2}{*}{$\begin{array}{l}\text { Torso Lean } \\
\text { Right } \bigcirc\end{array}$} & \multirow{2}{*}{ No $\bigcirc$ Left $\bigcirc$ Fwd } & \multirow{2}{*}{$\begin{array}{l}\text { Gender } \\
\bigcirc \mathbf{M} \bigcirc \mathbf{F}\end{array}$} & \multicolumn{2}{|l|}{ Hair } & \multirow{2}{*}{$\begin{array}{c}\text { Clear } \\
\text { All }\end{array}$} \\
\hline & & & Dk & اt & \\
\hline \multicolumn{2}{|l|}{ Weight } & \multicolumn{2}{|l|}{ Age } & \multicolumn{2}{|c|}{ Sunglasses } \\
\hline Lean $\bigcirc$ & Heavy $\bigcirc$ Obese & $\odot<30 \bigcirc 30-60$ & $>60$ & ( ) 1 & $\mathbf{N}$ \\
\hline
\end{tabular}

Figure 5. Part of the coding tool that records driver posture, gender, general hair color, whether wearing sunglasses, and weight and age category

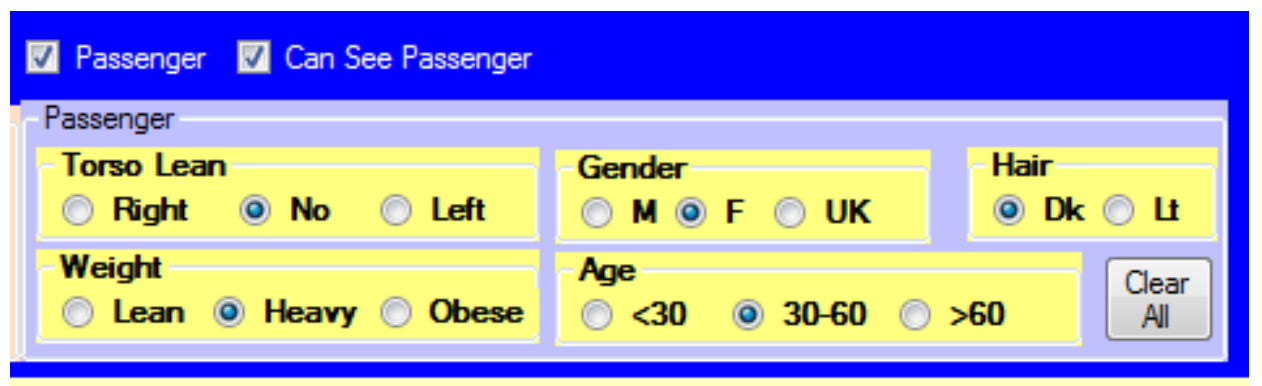

Figure 6. Part of the coding tool that records front passenger posture, gender (if can be determined from the video), general hair color, and weight and age category
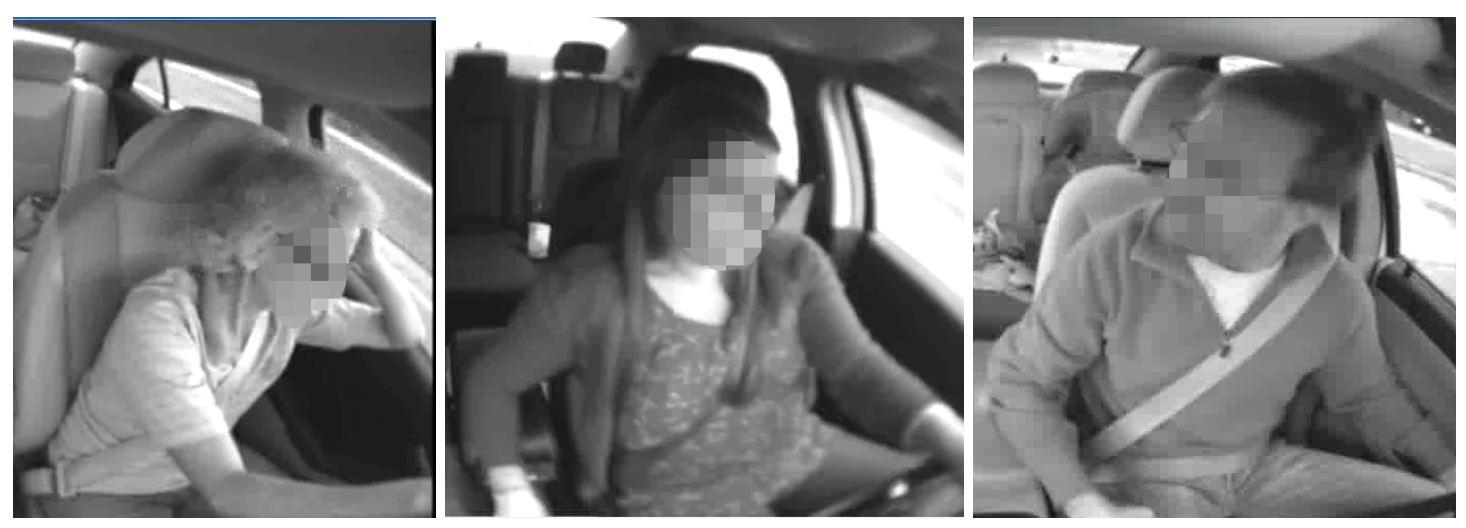

Figure 7. Examples of leaning left, right and forward (from left to right) 


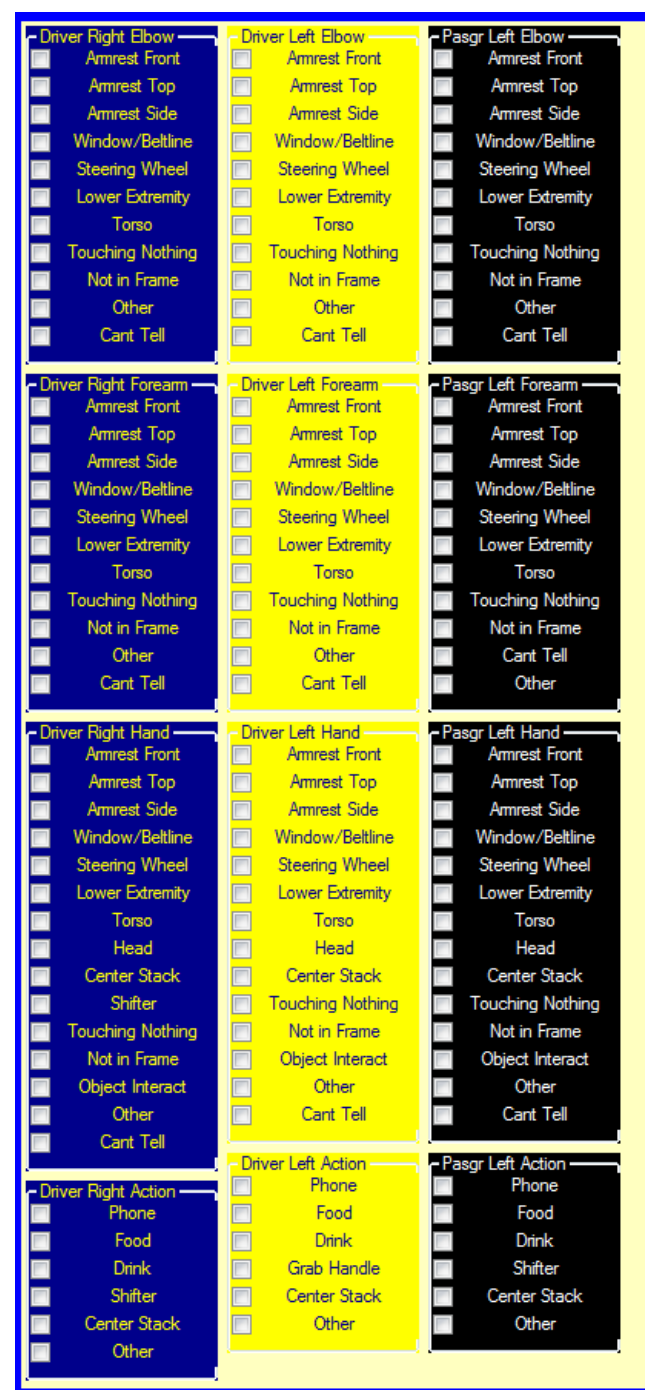

Figure 8. In the upper limb coding section of coding tool: blue and yellow columns are the right and left sides of the driver respectively and the black column is the left side of the front passenger if present. The rows from top to bottom are the body parts: elbow location, forearm location, hand location, and the most frequently objects which with the occupants interacted.

Table 5

Driver Arm Location and Object Interaction Checkboxes in Coding Tool

\begin{tabular}{|c|c|c|c|c|}
\hline \multicolumn{2}{|c|}{$\begin{array}{l}\text { Elbow, Forearm and Hand Locations } \\
\text { (Left and Right) }\end{array}$} & $\begin{array}{l}\text { Additional Right } \\
\text { Hand Locations }\end{array}$ & $\begin{array}{l}\text { Left Hand } \\
\text { Interaction } \\
\text { Objects }\end{array}$ & $\begin{array}{l}\text { Right Hand } \\
\text { Interaction Objects }\end{array}$ \\
\hline $\begin{array}{l}\text { Armrest Front } \\
\text { Armrest Side } \\
\text { Armrest Top } \\
\text { Torso (Self) } \\
\text { Lower Extremity (Self) } \\
\text { Steering Wheel }\end{array}$ & $\begin{array}{l}\text { Window/Beltline } \\
\text { Touching Nothing } \\
\text { Not in Frame } \\
\text { Cannot Tell } \\
\text { Other* }\end{array}$ & $\begin{array}{l}\text { Head } \\
\text { Center Stack } \\
\text { Shifter } \\
\text { Object Interact }\end{array}$ & $\begin{array}{l}\text { Drink } \\
\text { Food } \\
\text { Phone } \\
\text { Grab Handle } \\
\text { Other* }\end{array}$ & $\begin{array}{l}\text { Drink } \\
\text { Food } \\
\text { Phone } \\
\text { Shifter } \\
\text { Center Stack } \\
\text { Other* }\end{array}$ \\
\hline
\end{tabular}

*Requires rare events code 
Table 6

Front Passenger Arm Location and Object Interaction Checkboxes in Coding Tool

\begin{tabular}{|ll|l|}
\hline \multicolumn{2}{|c|}{ Left Elbow, Forearm and Hand Locations } & \multicolumn{1}{|c|}{ Left Hand Interaction Objects } \\
\hline Armrest Front & Shifter & Drink \\
Armrest Side & Object Interact & Food \\
Armrest Top & Touching Nothing & Phone \\
Torso (Self) & Not in Frame & Shifter \\
Lower Extremity (Self) & Cannot Tell & Center Stack \\
Head (Self) & Other* & Other* \\
Center Stack & & \\
\hline
\end{tabular}

* Requires rare events code

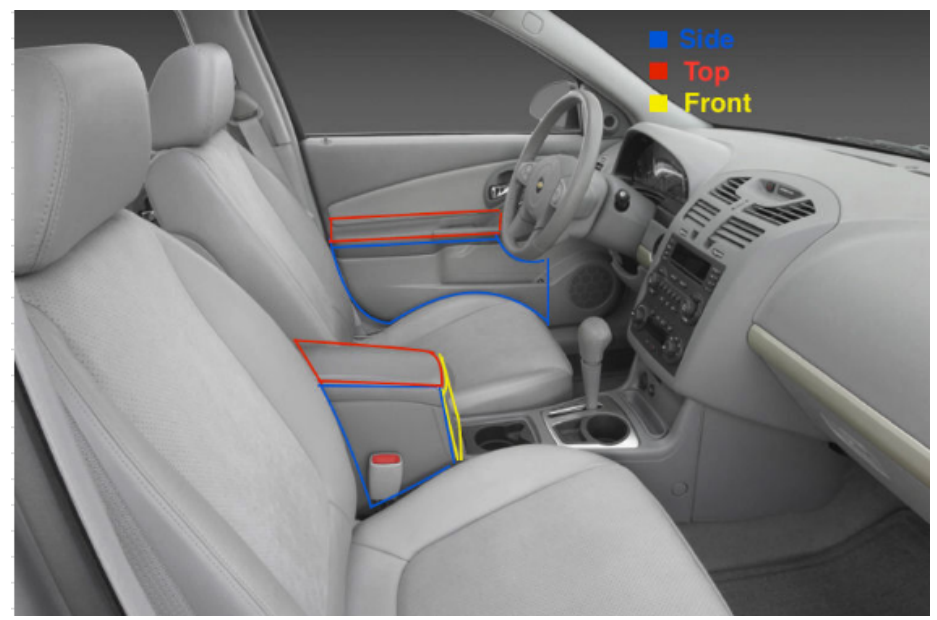

Figure 9. Armrest regions

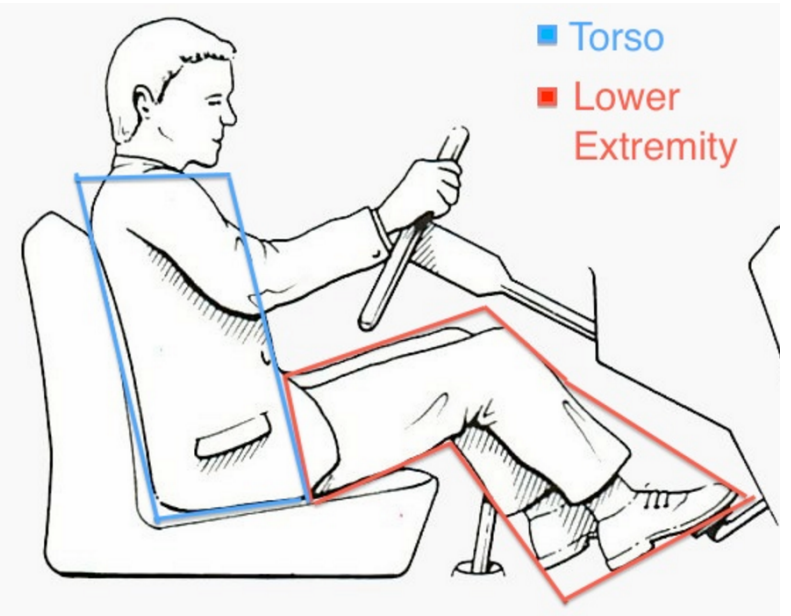

Figure 10. Body regions the arm might be coded to contact 


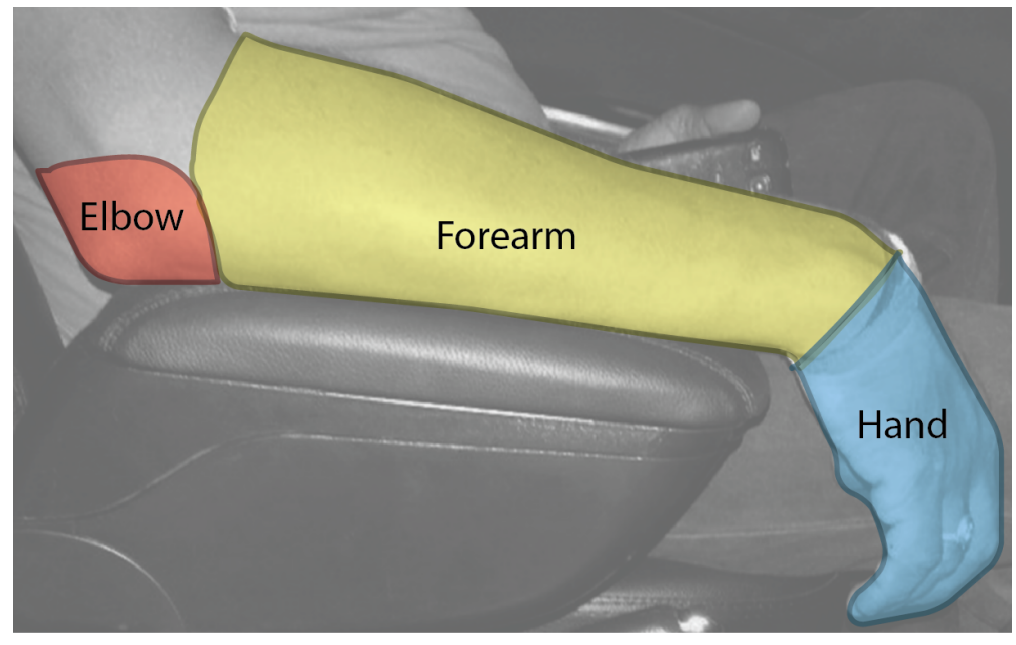

Figure 11. Arm regions

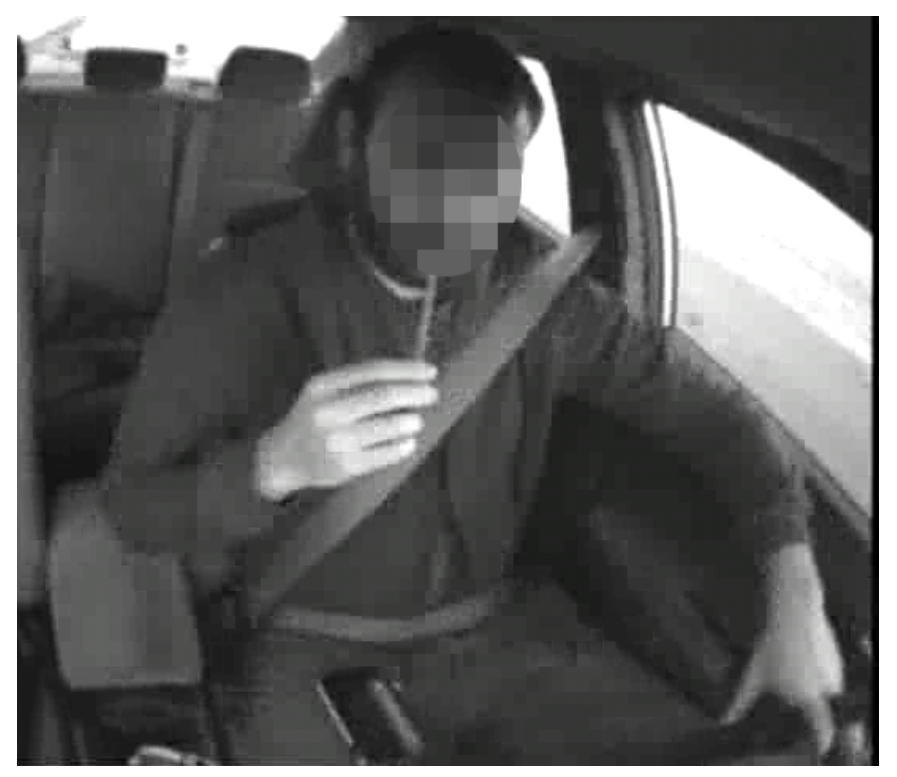

Figure 12. Example of right elbow on top of armrest, forearm touching nothing, right hand interacting with an object, left elbow on beltline/window, left forearm touching nothing, left hand on steering wheel, phone on lap and an unidentified object in cupholder 


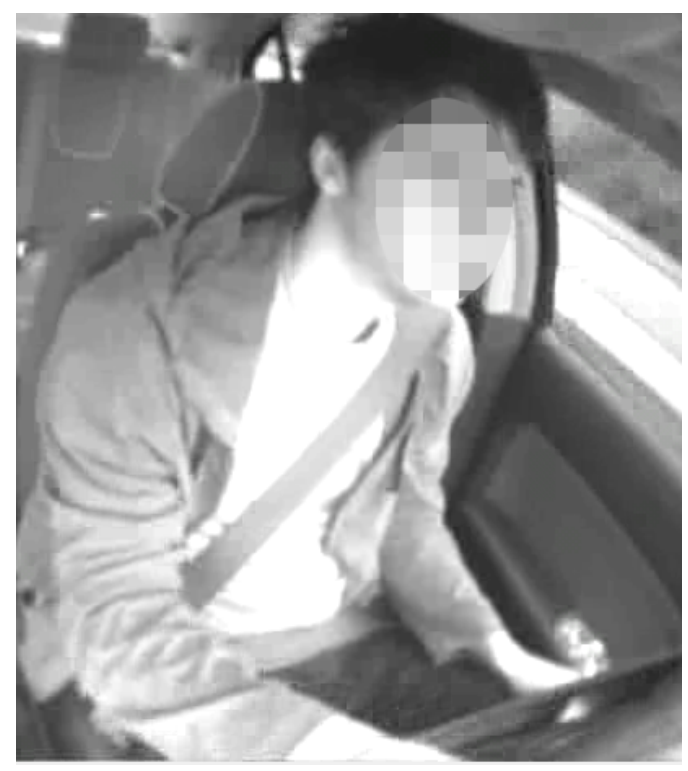

Figure 13. Example of right and forearm touching nothing, right hand on steering wheel, left elbow touching torso, left forearm touching nothing, and left hand touching lower extremity

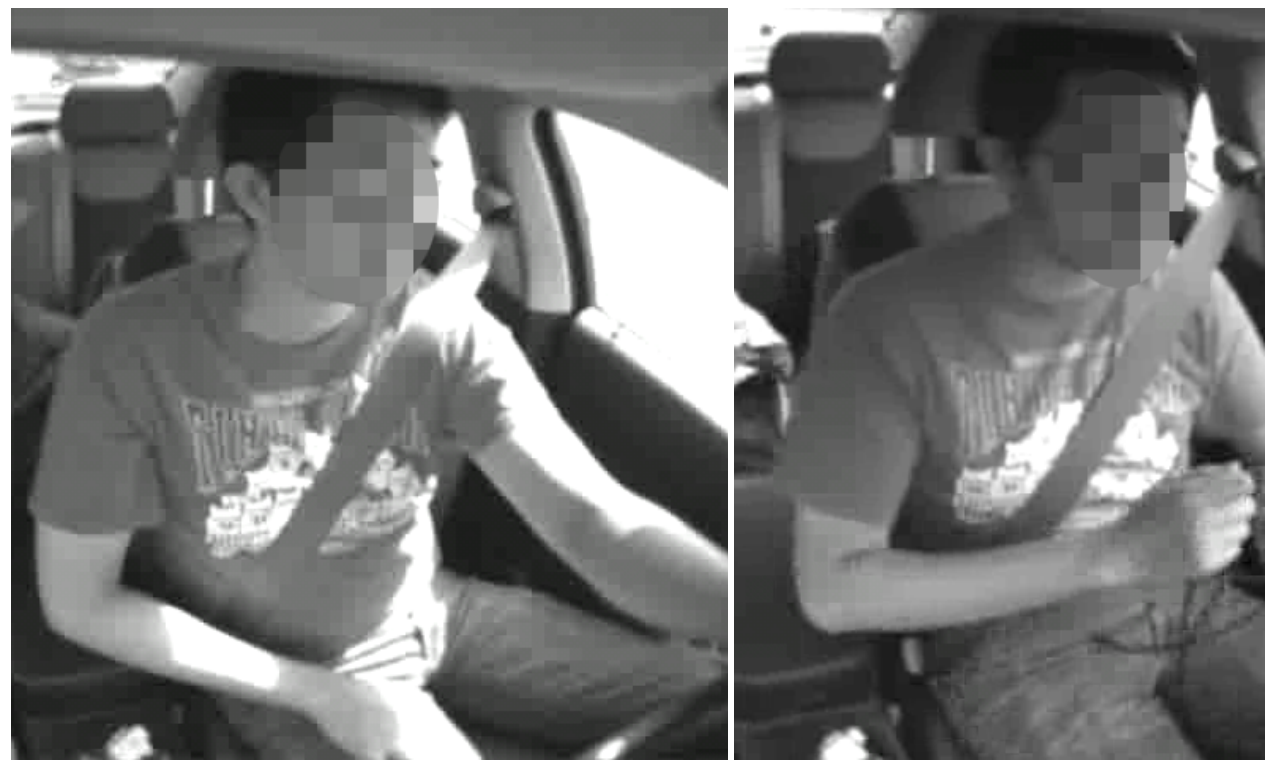

Figure 14. Example of elbow and forearm (left) versus just the elbow touching the top of the armrest (right) 


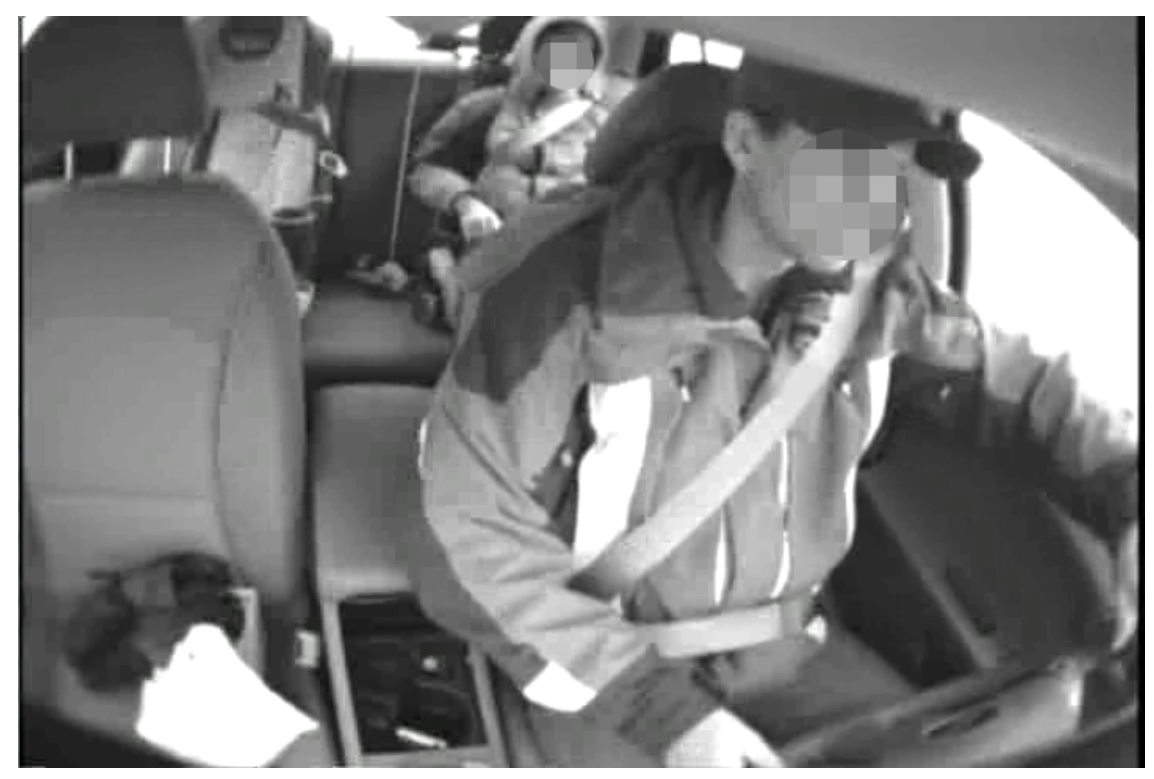

Figure 15. Example of driver with elbow in the beltline
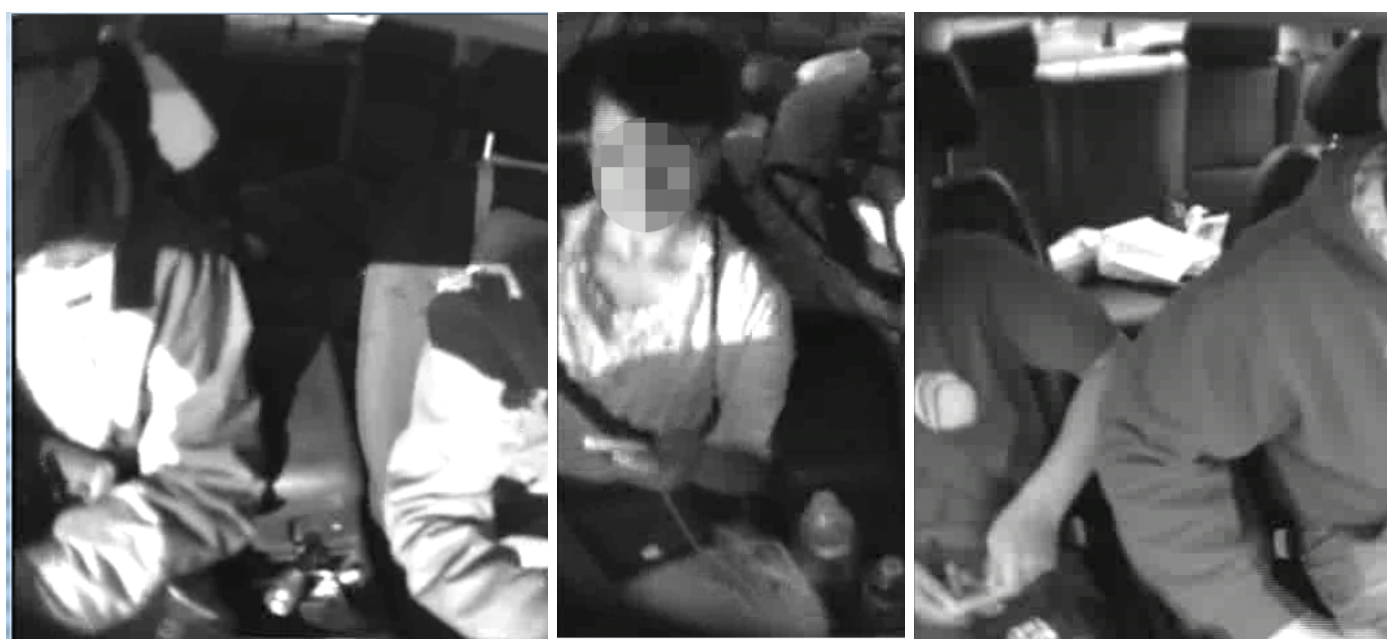

Figure 16. Example of a passengers with elbow touching front of armrest (left), side of the armrest (middle), and of a passenger with elbow and forearm touching the top of the armrest (right) 


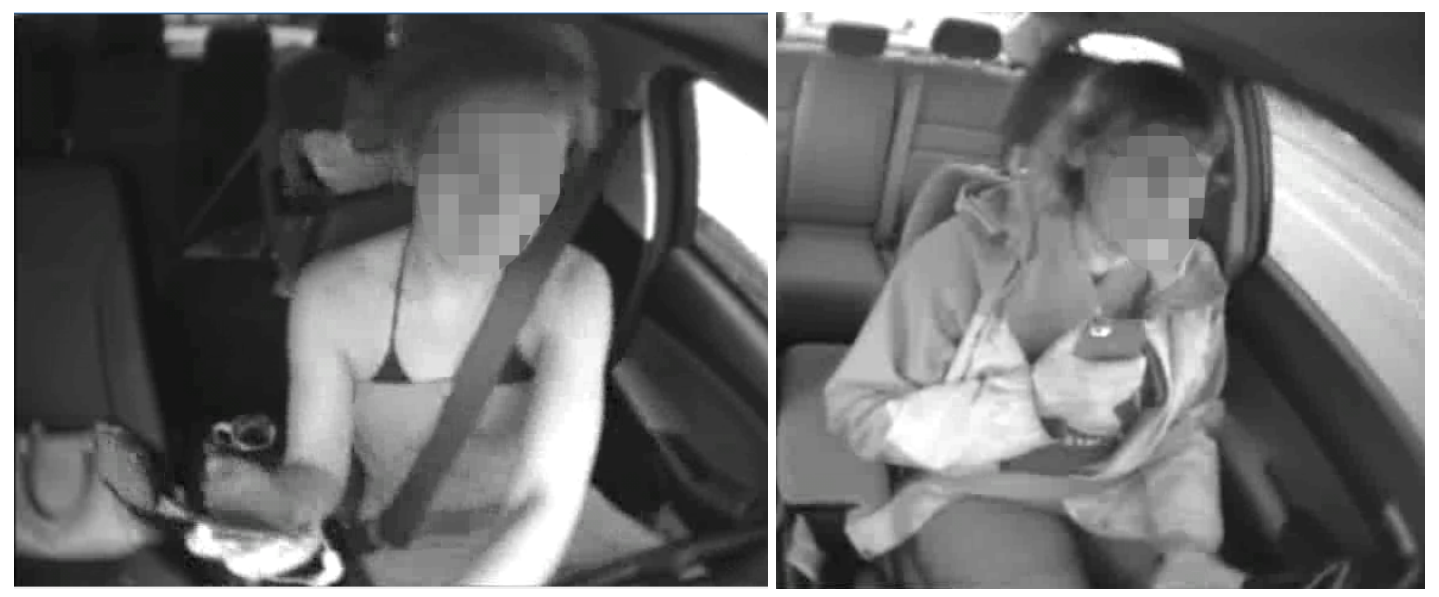

Figure 17. Examples of phones in right hand and elbow on top of armrest

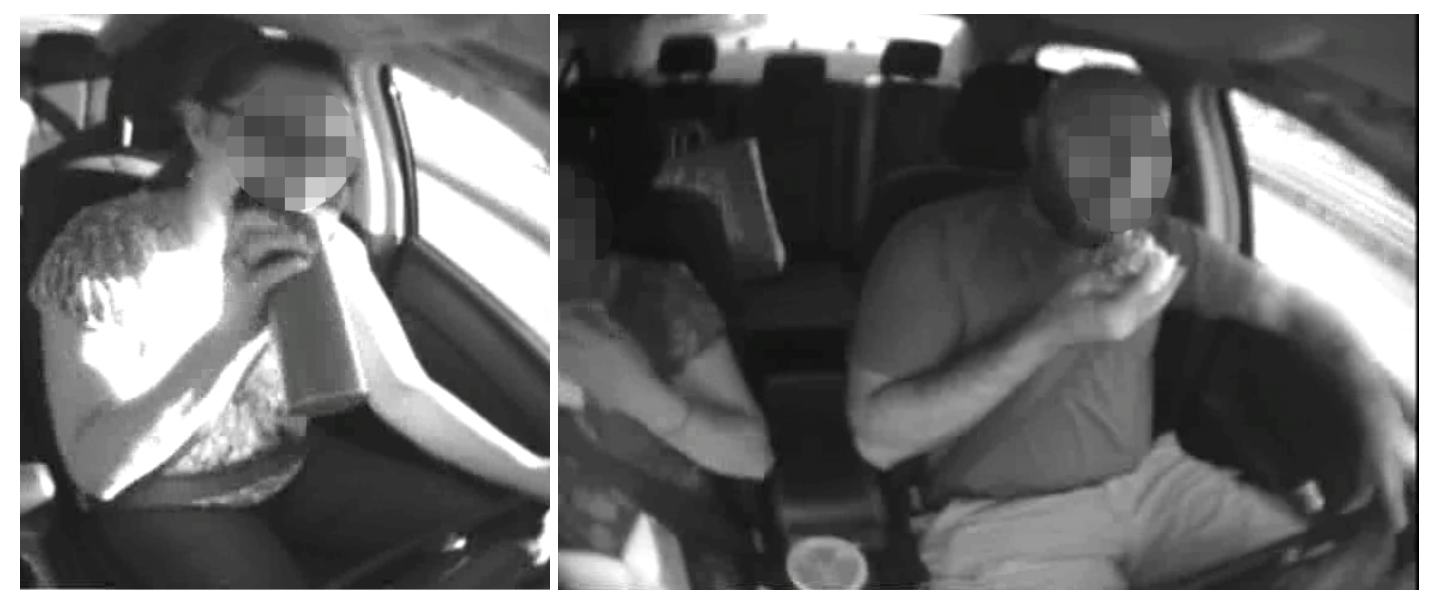

Figure 18. Examples of drink (left) and food (right) in right hand
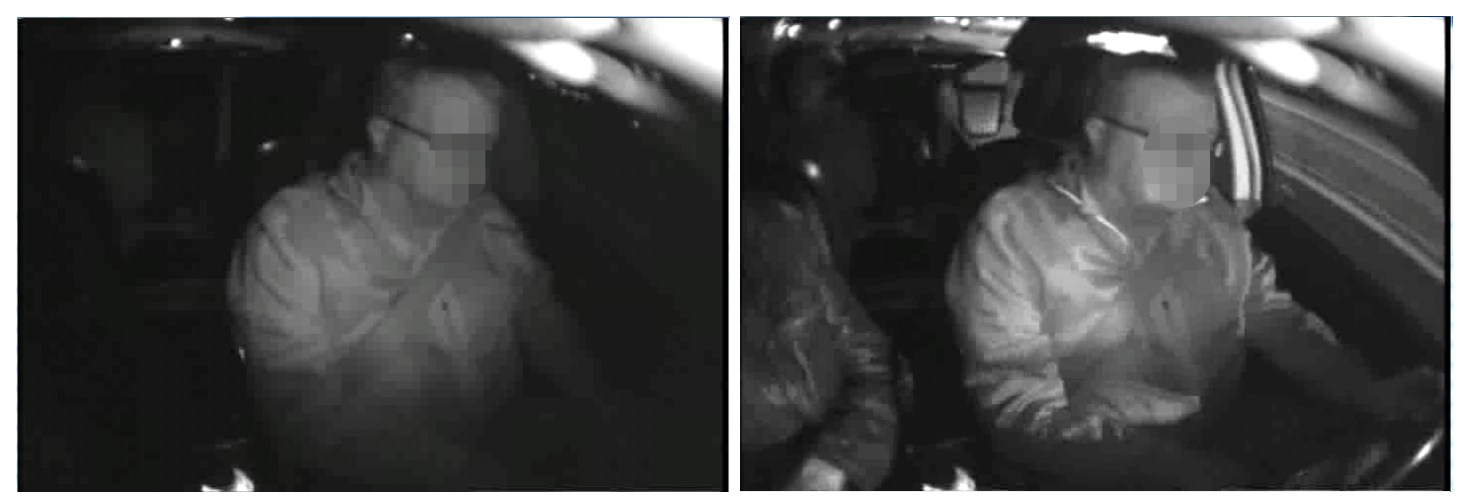

Figure 19. Example of "Can't tell" on left, though reviewers were instructed to scrub forward or backward several frames to get more information to do the coding 


\section{Rare Events}

To keep the form from being too crowded, rare events were entered in the notes area of the coding tool (Figure 20). The wording of the rare events notes was standardized into a four-word pattern which included 1) the occupant position 2) the who, what or where 3) direction, side, or type of action and 4) the item, type of occurrence, duration or other descriptor. The codes were organized into a spreadsheet that all coders used. Once a code was developed, it was copied and pasted into the coding tool for any following occurrences. Rare events coded are listed in Tables 7-9, with examples in Figures 21 - 22.

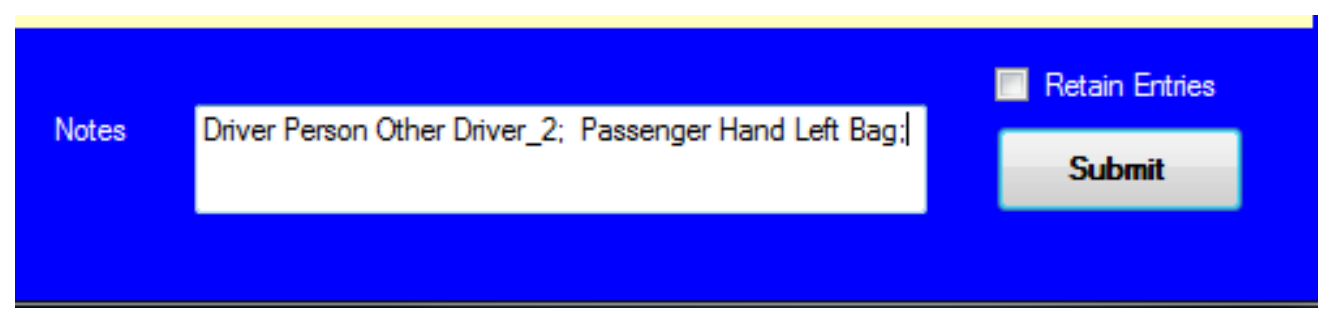

Figure 20. An example of entering rare events in notes area of coding tool in which the first entry indicates that it is "Driver 2" instead of "Driver 1", and the second entry records that the left hand of the passenger is touching a bag.

Table 7

Driver Position Rare Events

\begin{tabular}{|c|c|c|}
\hline Right Hand Interaction & Left Hand Interaction & $\begin{array}{l}\text { Other Body Parts } \\
\text { Occurrences }\end{array}$ \\
\hline $\begin{array}{l}\text { Left Arm (Self) } \\
\text { Left Hand (Self) } \\
\text { Cigarette } \\
\text { Console } \\
\text { Driver Floor } \\
\text { Rear Floor } \\
\text { Lotion } \\
\text { Money } \\
\text { Paper } \\
\text { Pen } \\
\text { Ponytail } \\
\text { Purse } \\
\text { Sun Visor } \\
\text { Passenger Seat } \\
\text { Rear Seat } \\
\text { Front Seat Passenger } \\
\text { Rear Seat Passenger }\end{array}$ & $\begin{array}{l}\text { Right Arm (Self) } \\
\text { Right Hand (Self) } \\
\text { Cigarette } \\
\text { Door } \\
\text { Driver Floor } \\
\text { Lotion } \\
\text { Paper } \\
\text { Ponytail } \\
\text { Sunglasses } \\
\text { Sun Visor } \\
\text { Front Seat Passenger }\end{array}$ & $\begin{array}{l}\text { Both Arms Crossed } \\
\text { Left Arm Outside } \\
\text { Shoulder Holding Phone } \\
\text { Left Knee Steering } \\
\text { Right Knee Steering } \\
\text { No One Steering } \\
\text { Driver Eyes Down on } \\
\text { Console }\end{array}$ \\
\hline
\end{tabular}


Table 8

Objects in the Vehicle Rare Events

\begin{tabular}{|c|c|c|c|c|}
\hline $\begin{array}{l}\text { Item on Center } \\
\text { Console or Center } \\
\text { Armrest }\end{array}$ & $\begin{array}{l}\text { Items in Center } \\
\text { Cup Holder }\end{array}$ & $\begin{array}{l}\text { Location of Sunglasses } \\
\text { Relative to Driver }\end{array}$ & $\begin{array}{l}\text { Item in Lap } \\
\text { of Driver }\end{array}$ & Seat Belt of Driver \\
\hline $\begin{array}{l}\text { Cup } \\
\text { Phone } \\
\text { Purse } \\
\text { Pet } \\
\text { Object* }\end{array}$ & $\begin{array}{l}\text { Cup } \\
\text { Cups } \\
\text { Food } \\
\text { Phone } \\
\text { Purse } \\
\text { Sunglasses } \\
\text { Object* }\end{array}$ & $\begin{array}{l}\text { Removing sunglasses } \\
\text { Sunglasses top of head } \\
\text { Sunglasses in mouth }\end{array}$ & $\begin{array}{l}\text { Pet } \\
\text { Phone } \\
\text { Purse } \\
\text { Object* }\end{array}$ & $\begin{array}{l}\text { Donning while driving } \\
\text { Donning while stopped } \\
\text { Not using } \\
\text { Adjusting Location }\end{array}$ \\
\hline
\end{tabular}

*reviewer is unable to identify what the object is

Table 9

Front Passenger Rare Events

\begin{tabular}{|l|l|l|l|l|}
\hline \multicolumn{2}{|c|}{ Left Hand Interaction } & \multicolumn{1}{|c|}{ Other Body Parts Occurrences } & \multicolumn{1}{c|}{ Lap } & In Seat \\
\hline Bag & Opening Console & Elbow in driver seat & Bag & Pet \\
Belt & Driver (Person) & Forearm on console while opening & Pet & \\
$\begin{array}{l}\text { Computer } \\
\text { Console }\end{array}$ & Driver Seat & & Purse & \\
\hline
\end{tabular}
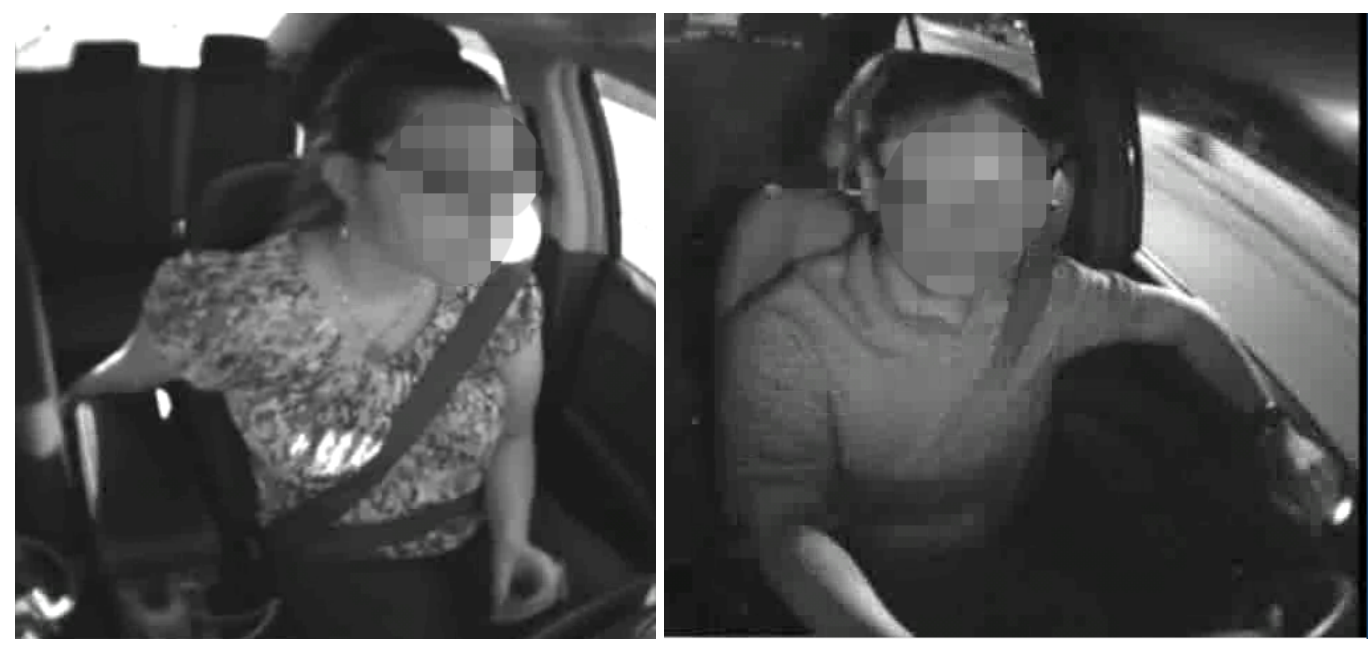

Figure 21. Rare events examples of right hand in rear seat area (left) and a cigarette in left hand (right) 

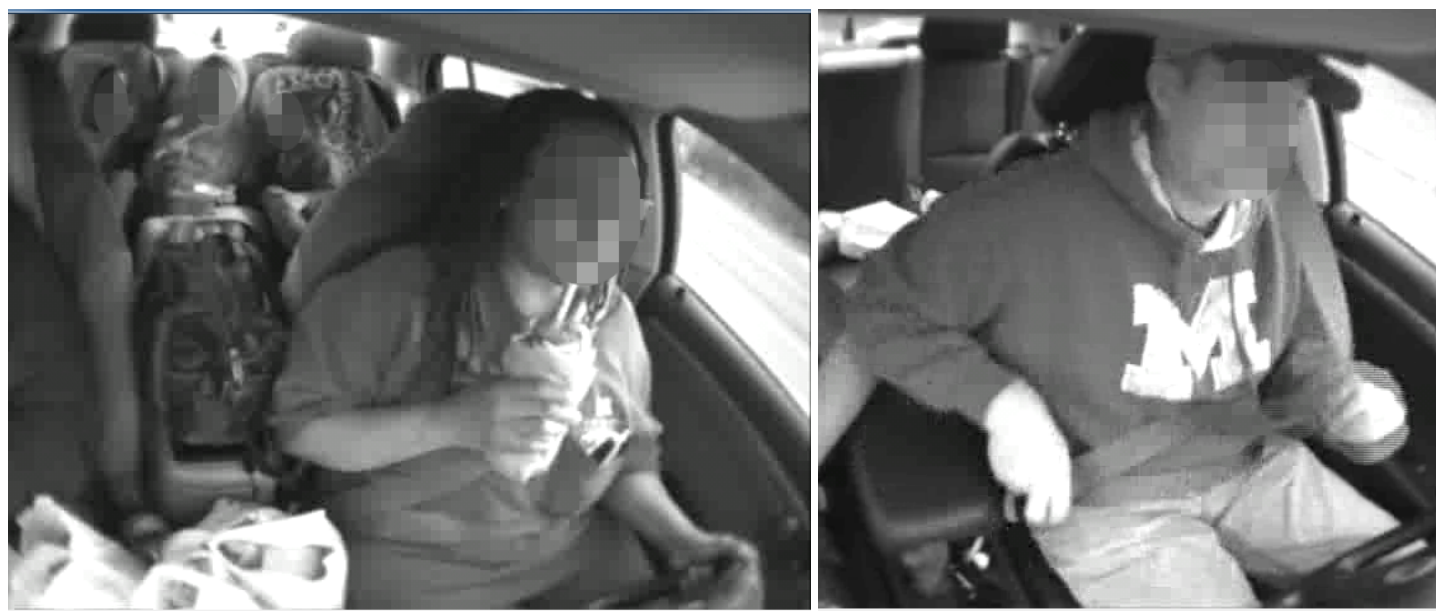

Figure 22. Examples rare events of objects in vehicle: food in console area (left) and donning seat belt (right)

\section{Sampling Strategy}

Vehicles in the SPMD dataset that had data from at least 100 separate trips and traveled over 1000 miles over the course of SPDM were included. In these vehicles, only trips that lasted longer than 5 minutes were included. Ten trips with duration of greater than 5 minutes were selected from each of the vehicles and 10 frames were coded for each trip. Within each trip the first coded frame was 10 seconds after the start of the video and the last frame was 5 seconds from end of video. The remaining 8 frames were equally spaced over the duration of the trip. The trips were then assigned to the reviewers and placed in an interactive table (Figure 23) from which they could click a link that brought the video up in the viewer at the frame to be coded.

Based on this sampling strategy, approximately $25 \%$ of the trips were at night (after sunset and before sunrise). Trip length ranged from 5 minutes to 2.5 hours with an average trip length of 16 minutes (Figure 24). 


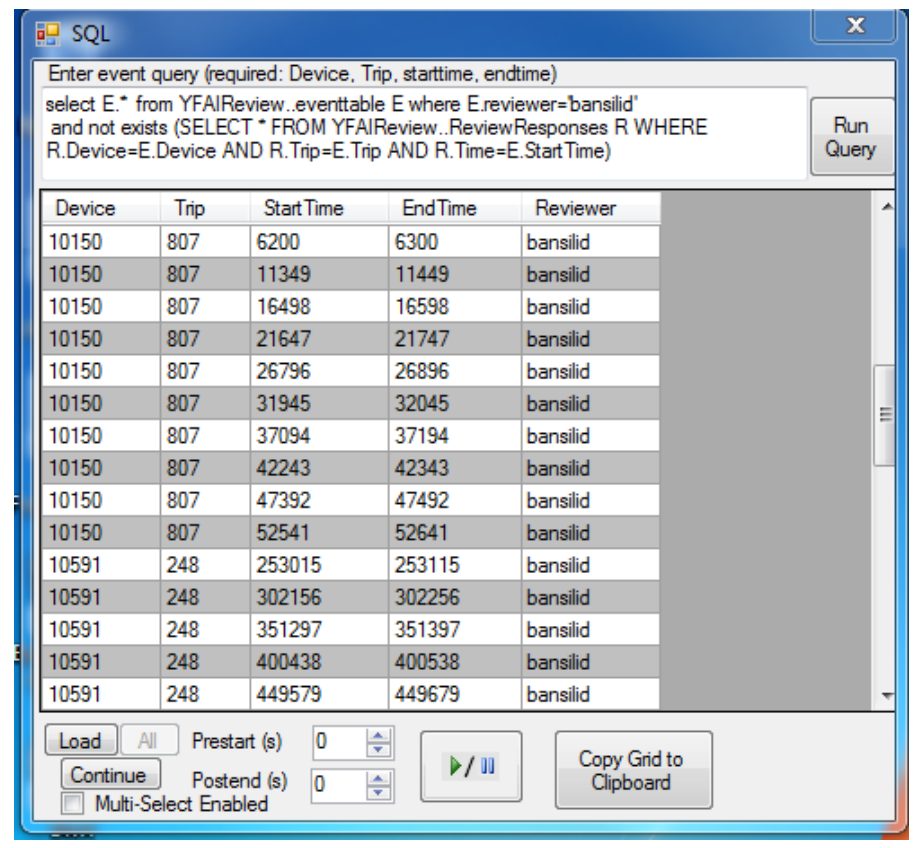

Figure 23. Example of table generated for each reviewer with list of frames to code and hyperlinks to the video frame (device is the vehicle code)

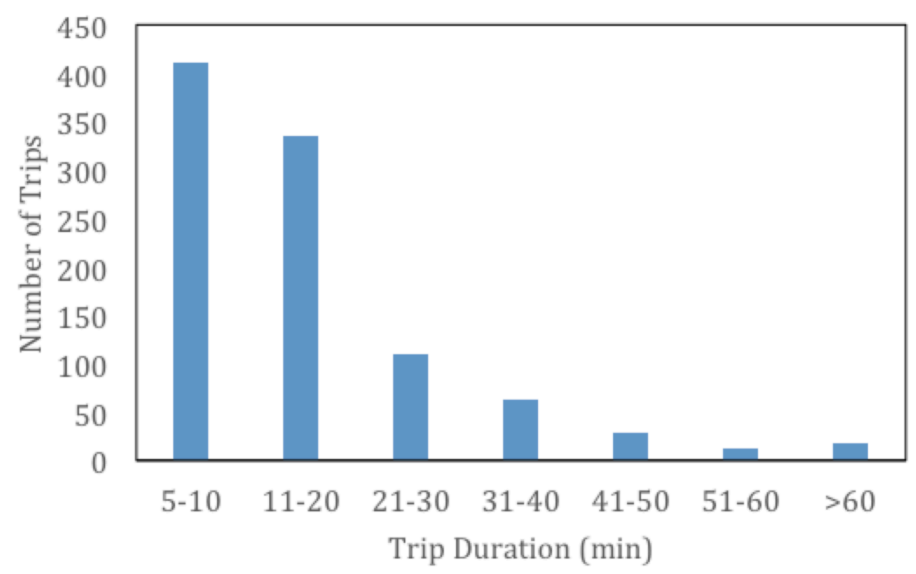

Figure 24. Frequency of trip lengths in data sampled 


\section{RESULTS}

A total of 9856 video frames were coded. In less than $2 \%$ of these frames, driver data were not available, either due to obstruction of the camera view or the driver not being in the vehicle. All percentages reported below exclude those frames from the denominator.

The responses were tallied for each question and across all responses the notes field. The Appendix contains tallies for all responses. Tables 10 and 11 list summary statistics regarding the driver's upper extremity postures and actions. The driver's right elbow or forearm was in contact with the console armrest in 36\% of frames, with the contact on the top of armrest more than three times as frequently as with the front. Elbow or forearm contact with other parts of the armrest observed in less than $1 \%$ of frames. The driver's right hand was in contact with any part of the armrest in less than 1\% of frames. Drivers' right hands were in contact with the steering wheel in $45 \%$ of frames and interacting with an object in about $10 \%$ of frames, including in contact with a phone in $6 \%$ of frames.

Coding of the driver's left upper extremity was more challenging due to the camera angle, with the results indeterminate in about $10 \%$ of frames, depending on the body part. In about $10 \%$ of frames, the driver's left elbow was in contact with the door armrest and on the window/beltline in about $7 \%$ of frames. The driver's left hand was in contact with the steering wheel about twice as frequently as the right hand and interacting with objects, including phones, about half as frequently. Drivers had both hands on the steering wheel in about $28 \%$ of frames.

As noted above, passenger data were sparse. In about $8 \%$ of the frames, a passenger was present and had a forearm or elbow in contact with the top of the center console armrest.

Among the observations coded in the notes section of the input form, only a few were seen in $1 \%$ or more of frames. A cup or other beverage container was observed in the console cupholder in $12 \%$ of frames, although the cupholder was difficult to see in some vehicles. Some other object was observed in the cupholder about $2 \%$ of the time.

The Appendix contains tabulations of frequencies for each coded variable. For the notes section, the frequency of occurrence of each response from the coders is tabulated. Among the observations:

- in $60 \%$ of coded frames the driver was a woman,

- drivers were wearing sunglasses in $17 \%$ of frames,

- drivers were leaning appreciably left or right in less than $1 \%$ of frames, and

- $\quad$ the driver had a phone in his or her lap in about $2 \%$ of frames. 
Table 10

Driver Right Upper-Extremity Posture and Actions

Driver Right Elbow

Touching Nothing

Armrest Top

Torso

Can't Tell

Armrest Front

Armrest Side

Other

Lower Extremity

Not in Frame

\section{Driver Right Hand}

Steering Wheel

Lower Extremity

Object Interact

Not in Frame

Can't Tell

Touching Nothing

Head

Other

Shifter

Center Stack

Torso

Armrest Front

Armrest Side

Armrest Top

Window/Beltline

\section{Driver Right Forearm}

$55.2 \%$

Touching Nothing

6923

$72.1 \%$

$28.2 \%$

Armrest Top

824

763

$8.6 \%$

$8.0 \%$

Can't Tell

$6.1 \%$

Lower Extremity

559

392

$7.9 \%$

$1.3 \%$

Torso

$0.4 \%$

Not in Frame

$0.3 \%$

$0.3 \%$

$0.2 \%$

Other

Armrest Side

Armrest Front

Steering Wheel

\section{Driver Right Action}

4392

$45.7 \%$

No Action

8601

$89.6 \%$

$13.4 \%$

Phone

628

$6.5 \%$

943

897

822

352

268

180

$9.8 \%$

Drink

126

$1.3 \%$

$9.3 \%$

Other

116

$1.2 \%$

$8.6 \%$

Food

112

$1.2 \%$

$3.7 \%$

Shifter

$2.8 \%$

Center Stack

$1.9 \%$

162

$1.7 \%$

$1.3 \%$

$1.1 \%$

106

$0.4 \%$

$0.1 \%$

$\begin{array}{ll}14 & 0.1 \% \\ 11 & 0.1 \%\end{array}$

6

$0.1 \%$ 
Table 11

Driver Left Upper-Extremity Posture and Actions

Driver Left Elbow

Touching Nothing

Can't Tell

Armrest Top

Torso

Window/Beltline

Lower Extremity

Armrest Side

Not in Frame

Other

Steering Wheel

Armrest Front

\section{Driver Left Hand}

Steering Wheel

Can't Tell

Lower Extremity

Head

Object Interact

Touching Nothing

Other

Not in Frame

Window/Beltline

Torso

Armrest Top

Armrest Front

Armrest Side

$\begin{array}{rr}5695 & 59.3 \% \\ 1087 & 11.3 \% \\ 1053 & 11.0 \% \\ 909 & 9.5 \% \\ 659 & 6.9 \% \\ 92 & 1.0 \% \\ 64 & 0.7 \% \\ 27 & 0.3 \% \\ 15 & 0.2 \% \\ 1 & 0.0 \% \\ 1 & 0.0 \%\end{array}$

6126

1125

956

435

381

213

133

81

55

46

42

8

2

\section{Driver Left Forearm}

$\begin{array}{lrr}\text { Touching Nothing } & 6407 & 66.7 \% \\ \text { Lower Extremity } & 1276 & 13.3 \% \\ \text { Can't Tell } & 1131 & 11.8 \% \\ \text { Torso } & 302 & 3.1 \% \\ \text { Armrest Top } & 238 & 2.5 \% \\ \text { Window/Beltline } & 164 & 1.7 \% \\ \text { Not in Frame } & 45 & 0.5 \% \\ \text { Other } & 23 & 0.2 \% \\ \text { Steering Wheel } & 10 & 0.1 \% \\ \text { Armrest Side } & 7 & 0.1 \%\end{array}$

\section{Driver Left Action}

$\begin{array}{lrr}\text { No Action } & 9145 & 95.2 \% \\ \text { Phone } & 247 & 2.6 \% \\ \text { Other } & 108 & 1.1 \% \\ \text { Drink } & 73 & 0.8 \% \\ \text { Food } & 29 & 0.3 \% \\ \text { Grab Handle } & 1 & 0.0 \%\end{array}$

\section{Covariate Effects}

Chi-square analysis demonstrated that some aspects of upper-extremity posture were associated with driver and vehicle attributes. Male drivers were about 4 times as likely to rest their left elbow on the window/beltline than female drivers $(12 \%$ vs. $3 \%$ ). Men were also more likely than women to rest their elbows on the armrest (14\% vs. 9\%). Male and female drivers had their left hands on the steering wheel in approximately the same fraction of frames ( $61 \%$ vs. $65 \%)$.

Male drivers rested their right elbows on the top of center console armrest about twice as often as female drivers ( $40 \%$ vs. $20 \%$ ). The ratio for forearm contact was similar $(12 \%$ vs. $6 \%)$. Female drivers were more likely to be interacting with an object with the right hand (11\% vs $7 \%$ ) but the fraction of frames with the right 
hand on the steering wheel was similar for men and women ( $42 \%$ vs. $48 \%$ ). Female drivers were more frequently holding a phone in the right hand than male drivers (7.5\% vs. $4.8 \%)$. Women were about twice as likely to wear sunglasses during the $75 \%$ of trips taken during the day ( $29 \%$ vs. $15 \%$ ).

A potentially interesting relationship between vehicle model and console armrest use was observed. Table 11 shows tabulated observations for a binary variable indicating whether the right elbow was in contact with the top of the armrest. As noted above, women outnumber men in the sample, and women were less likely than men to use the console armrest. Only data from vehicle models for which at least 500 frames were coded and the data were collapsed across model years to obtain $>500$ samples per vehicle. The fraction of coded frames with male drivers varied across vehicles, from $70 \%$ in the Impala to $28 \%$ in the Civic. For women, the use of the armrest was similar across vehicles between $19 \%$ and $26 \%$ of frames. However, the usage rate for men was markedly different across vehicles, ranging from $69 \%$ in the Impala to a low of $25 \%$ in the Civic.

Table 11

Use of Console Armrest by Vehicle Model and Gender

\begin{tabular}{|c|c|c|c|c|c|c|}
\hline Elbow On Top & Aura & Civic & Fusion & G6 & Impala & Malibu \\
\hline 0 & 711 & 2324 & 1776 & 513 & 269 & 809 \\
\hline 1 & 360 & 656 & 675 & 182 & 331 & 495 \\
\hline 0 & $66 \%$ & $78 \%$ & $72 \%$ & $74 \%$ & $45 \%$ & 62 \\
\hline 1 & $34 \%$ & $22 \%$ & $28 \%$ & $26 \%$ & $55 \%$ & 38 \\
\hline Fraction Male & $47.2 \%$ & $28.0 \%$ & $51.0 \%$ & $23.7 \%$ & $70.0 \%$ & 36.4 \\
\hline
\end{tabular}

MALE

\begin{tabular}{rrrrrrrr} 
& Aura & \multicolumn{2}{c}{ Civic } & \multicolumn{2}{c}{ Fusion } & G6 & \multicolumn{2}{c}{ Impala } & Malibu \\
0 & 275 & 621 & 859 & 82 & 129 & 192 \\
1 & 230 & 212 & 390 & 83 & 291 & 283 \\
& & & & & & \\
0 & $54 \%$ & $75 \%$ & $69 \%$ & $50 \%$ & $31 \%$ & $40 \%$ \\
1 & $46 \%$ & $25 \%$ & $31 \%$ & $50 \%$ & $69 \%$ & $60 \%$
\end{tabular}

FEMALE

\begin{tabular}{rrrrrrr}
\multicolumn{2}{c}{ Aura } & \multicolumn{2}{c}{ Civic } & \multicolumn{2}{c}{ Fusion } & \multicolumn{2}{c}{ Impala } & \multicolumn{2}{c}{ Malibu } \\
0 & 436 & 1703 & 917 & 431 & 140 & 617 \\
1 & 130 & 444 & 285 & 99 & 40 & 212 \\
& & & & & & \\
0 & $77 \%$ & $79 \%$ & $76 \%$ & $81 \%$ & $78 \%$ & $74 \%$ \\
1 & $23 \%$ & $21 \%$ & $24 \%$ & $19 \%$ & $22 \%$ & $26 \%$
\end{tabular}




\section{DISCUSSION}

This study is the first to look in detail at driver upper extremity postures in a large sample of naturalistic data. The data show that the inboard (console) armrest is used about twice as often as the outboard (door) armrest. Drivers had their left hands on the steering wheel more often than their right hands and interacted with other objects, including the vehicle console, more often with their right hands. The data showed some strong gender effects, with men more likely to use the armrests on both sides. This may be due in part to the armrests being fixed with respect to the vehicle while the seat moves fore-aft to accommodate drivers' body sizes. Women, who on average sit further forward, experience armrests that are on average further rearward relative to their body position.

The analysis by vehicle model showed some differences in male armrest use across vehicles, although the sample sizes are relatively small when looking at individual vehicle models. Nonetheless, these results suggest that it may be interesting to look at the extent to which armrest design affects driver's armrest usage patterns, and how the design interacts with driver body size. The current sample of vehicle models did not including any seat-mounted armrest designs, which would provide a more consistent experience independent of seat position.

Comparison data in the literature are sparse. Walton and Thomas (2005) reported drivers using two hands in $25 \%$ of on-road observations, consistent with the current study. However, that study was conducted in New Zealand using roadside observations rather than in-vehicle camera data.

This study is limited primarily by the sample size with respect to drivers and vehicle models. The data included 165 unique drivers in 100 vehicles; 50 or more frames were coded for 92 drivers. The relatively small number of drivers reduces the ability to assess the associations with drivers' attributes such as gender. The limited number of vehicles is also a substantial limitation. All were midsize sedans with front bucket seats. Vehicles from other market segments, such as pickup trucks and SUVs, may have produced different data. Future studies should examine upperextremity activities across a wider range of vehicles. Improved camera coverage and higher video resolution would reduce the number of frames in which the activities could not be discerned. 


\section{REFERENCES}

Bezzina, D., \& Sayer, J. (2015). Safety pilot model deployment: Test conductor team report. (Report No. DOT HS 812 171). Washington, DC: National Highway Traffic Safety Administration.

Walton, D., and Thomas, J.A. (2005). Naturalistic observations of driver hand positions. Transportation Research Part F, 8:229-238 


\section{APPENDIX}

\section{Tabulated Data Tallies}

\begin{tabular}{|c|c|c|c|c|c|}
\hline Dri_Gender & Count & Fraction & Dri_Age & Count & Fraction \\
\hline $\mathrm{F}$ & 5862 & $61.0 \%$ & 3060 & 6608 & $68.8 \%$ \\
\hline \multirow[t]{2}{*}{ M } & 3741 & $39.0 \%$ & LT30 & 2316 & $24.1 \%$ \\
\hline & & & GT60 & 679 & $7.1 \%$ \\
\hline \multicolumn{6}{|l|}{ Dri_Hair } \\
\hline Dark & 5914 & $61.6 \%$ & & & \\
\hline \multirow[t]{2}{*}{ Light } & 3689 & $38.4 \%$ & Dri_Weight & & \\
\hline & & & Lean & 6263 & $65.2 \%$ \\
\hline Dri_TorsoLean & & & Heavy & 2918 & $30.4 \%$ \\
\hline No & 9215 & $96.0 \%$ & Obese & 422 & $4.4 \%$ \\
\hline Forward & 184 & $1.9 \%$ & & & \\
\hline Left & 173 & $1.8 \%$ & Dri_Sunglasses & & \\
\hline \multirow[t]{2}{*}{ Right } & 31 & $0.3 \%$ & $\mathrm{~N}$ & 7961 & $82.9 \%$ \\
\hline & & & $\mathrm{Y}$ & 1642 & $17.1 \%$ \\
\hline \multicolumn{6}{|l|}{ Pas_Present } \\
\hline FALSE & 7759 & $80.8 \%$ & Pas_Gender & & \\
\hline \multirow[t]{2}{*}{ TRUE } & 1844 & $19.2 \%$ & Null & 7758 & $80.8 \%$ \\
\hline & & & $\mathrm{F}$ & 1082 & $11.3 \%$ \\
\hline Pas_Hair & & & M & 602 & $6.3 \%$ \\
\hline Null & 7998 & $83.3 \%$ & Unknown & 161 & $1.7 \%$ \\
\hline Dark & 1391 & $14.5 \%$ & & & \\
\hline \multirow[t]{2}{*}{ Light } & 214 & $2.2 \%$ & Pas_Age & & \\
\hline & & & Null & 8040 & $83.7 \%$ \\
\hline Pas_Weight & & & 3060 & 859 & $8.9 \%$ \\
\hline Null & 7885 & $82.1 \%$ & LT30 & 565 & $5.9 \%$ \\
\hline Lean & 1226 & $12.8 \%$ & GT60 & 139 & $1.4 \%$ \\
\hline Heavy & 452 & $4.7 \%$ & & & \\
\hline \multirow[t]{5}{*}{ Obese } & 40 & $0.4 \%$ & Pas_TorsoLean & & \\
\hline & & & Null & 7836 & $81.6 \%$ \\
\hline & & & No & 1739 & $18.1 \%$ \\
\hline & & & Left & 19 & $0.2 \%$ \\
\hline & & & Right & 9 & $0.1 \%$ \\
\hline
\end{tabular}




\begin{tabular}{|c|c|c|c|c|c|c|}
\hline \multicolumn{4}{|l|}{ Make } & \multicolumn{3}{|l|}{ Model } \\
\hline Honda & & 3024 & $31.5 \%$ & Civic & 2974 & $31.0 \%$ \\
\hline Ford & & 2823 & $29.4 \%$ & Fusion & 2423 & $25.2 \%$ \\
\hline Chevrolet & & 1895 & $19.7 \%$ & Malibu & 1296 & $13.5 \%$ \\
\hline Saturn & & 1071 & $11.2 \%$ & Aura & 1071 & $11.2 \%$ \\
\hline Pontiac & & 692 & $7.2 \%$ & G6 & 692 & $7.2 \%$ \\
\hline \multirow[t]{2}{*}{ Chevy } & & 98 & $1.0 \%$ & Impala & 597 & $6.2 \%$ \\
\hline & & & & Focus & 400 & $4.2 \%$ \\
\hline \multirow[t]{9}{*}{ Year } & & & & Malibu LTZ & 100 & $1.0 \%$ \\
\hline & 2010 & 2733 & $28.5 \%$ & Accord & 50 & $0.5 \%$ \\
\hline & 2008 & 1993 & $20.8 \%$ & & & \\
\hline & 2009 & 1577 & $16.4 \%$ & & & \\
\hline & 2012 & 1083 & $11.3 \%$ & & & \\
\hline & 2007 & 870 & $9.1 \%$ & & & \\
\hline & 2006 & 744 & $7.7 \%$ & & & \\
\hline & 2011 & 503 & $5.2 \%$ & & & \\
\hline & 2013 & 100 & $1.0 \%$ & & & \\
\hline
\end{tabular}


Dri_Lt_Elbow_1

Dri_Lt_Elbow_2

\begin{tabular}{|c|c|c|c|c|c|}
\hline Touching Nothing & 5695 & $59.3 \%$ & Null & 9574 & $99.7 \%$ \\
\hline Cant Tell & 1087 & $11.3 \%$ & Torso & 20 & $0.2 \%$ \\
\hline Armrest Top & 1053 & $11.0 \%$ & Armrest Top & 3 & $0.0 \%$ \\
\hline Torso & 909 & $9.5 \%$ & Armrest Side & 3 & $0.0 \%$ \\
\hline Window/Beltline & 659 & $6.9 \%$ & Window/Beltline & 2 & $0.0 \%$ \\
\hline Lower Extremity & 92 & $1.0 \%$ & Touching Nothing & 1 & $0.0 \%$ \\
\hline Armrest Side & 64 & $0.7 \%$ & & & \\
\hline Not in Frame & 27 & $0.3 \%$ & & & \\
\hline Other & 15 & $0.2 \%$ & Dri_Lt_Forearm_2 & & \\
\hline Steering Wheel & 1 & $0.0 \%$ & Null & 9593 & $99.9 \%$ \\
\hline \multirow[t]{2}{*}{ Armrest Front } & 1 & $0.0 \%$ & Torso & 7 & $0.1 \%$ \\
\hline & & & Touching Nothing & 2 & $0.0 \%$ \\
\hline Dri_Lt_Forearm_1 & & & Lower Extremity & 1 & $0.0 \%$ \\
\hline Touching Nothing & 6407 & $66.7 \%$ & & & \\
\hline Lower Extremity & 1276 & $13.3 \%$ & Dri_Lt_Hand_1 & & \\
\hline Cant Tell & 1131 & $11.8 \%$ & Steering Wheel & 6126 & $63.8 \%$ \\
\hline Torso & 302 & $3.1 \%$ & Cant Tell & 1125 & $11.7 \%$ \\
\hline Armrest Top & 238 & $2.5 \%$ & Lower Extremity & 956 & $10.0 \%$ \\
\hline Window/Beltline & 164 & $1.7 \%$ & Head & 435 & $4.5 \%$ \\
\hline Not in Frame & 45 & $0.5 \%$ & Object Interact & 381 & $4.0 \%$ \\
\hline Other & 23 & $0.2 \%$ & Touching Nothing & 213 & $2.2 \%$ \\
\hline Steering Wheel & 10 & $0.1 \%$ & Other & 133 & $1.4 \%$ \\
\hline \multirow[t]{2}{*}{ Armrest Side } & 7 & $0.1 \%$ & Not in Frame & 81 & $0.8 \%$ \\
\hline & & & Window/Beltline & 55 & $0.6 \%$ \\
\hline Dri_Lt_Hand_2 & & & Torso & 46 & $0.5 \%$ \\
\hline Null & 9472 & $98.6 \%$ & Armrest Top & 42 & $0.4 \%$ \\
\hline Steering Wheel & 68 & $0.7 \%$ & Armrest Front & 8 & $0.1 \%$ \\
\hline Object Interact & 49 & $0.5 \%$ & Armrest Side & 2 & $0.0 \%$ \\
\hline Lower Extremity & 9 & $0.1 \%$ & & & \\
\hline Head & 2 & $0.0 \%$ & Dri_Lt_Action_1 & & \\
\hline Touching Nothing & 1 & $0.0 \%$ & Null & 9145 & $95.2 \%$ \\
\hline Other & 1 & $0.0 \%$ & Phone & 247 & $2.6 \%$ \\
\hline \multirow[t]{2}{*}{ Armrest Side } & 1 & $0.0 \%$ & Other & 108 & $1.1 \%$ \\
\hline & & & Drink & 73 & $0.8 \%$ \\
\hline Dri_Lt_Action_2 & & & Food & 29 & $0.3 \%$ \\
\hline Null & 9603 & $100.0 \%$ & Grab Handle & 1 & $0.0 \%$ \\
\hline
\end{tabular}


Dri_Rt_Elbow_1

Dri_Rt_Forearm_1

Touching Nothing

$\begin{array}{rr}5297 & 55.2 \% \\ 2705 & 28.2 \% \\ 773 & 8.0 \% \\ 589 & 6.1 \% \\ 125 & 1.3 \% \\ 42 & 0.4 \% \\ 30 & 0.3 \% \\ 25 & 0.3 \% \\ 17 & 0.2 \%\end{array}$

Touching Nothing

6923

$72.1 \%$

Armrest Top

Armrest Top

$8.6 \%$

Torso

Cant Tell

824

$7.9 \%$

Cant Tell

Lower Extremity

$5.8 \%$

Armrest Front

Torso

$4.1 \%$

Armrest Side

Other

Lower Extremity

Not in Frame

$0.2 \%$

Not in Frame

$0.5 \%$

Other

$0.4 \%$

Armrest Side

$0.3 \%$

Armrest Front

$0.2 \%$

Steering Wheel

$0.0 \%$

Dri_Rt_Elbow_2

Null
Torso
Touching Nothing
Armrest Front

9584

$99.8 \%$

Dri_Rt_Forearm_2

$8 \quad 0.1 \%$

Null

9541

$99.4 \%$

$0.1 \%$

Torso

$0.0 \%$

Armrest Top

$0.2 \%$

Armrest Top

$0.0 \%$

Dri_Rt_Hand_1

Steering Wheel

Lower Extremity

4392

$45.7 \%$

1285

$13.4 \%$

Lower Extremity

$0.2 \%$

Armrest Side

$0.1 \%$

Touching Nothing

$0.1 \%$

$0.0 \%$

Cant Tell

$0.0 \%$

Armrest Front

$0.0 \%$

Object Interact

943

$9.8 \%$

Not in Frame

897

$9.3 \%$

Dri_Rt_Hand_2

Cant Tell

822

$8.6 \%$

Null

Touching Nothing

$3.7 \%$

Head

$2.8 \%$

Object Interact

9535

$99.3 \%$

Steering Wheel

$0.3 \%$

$0.3 \%$

Other

$1.9 \%$

Lower Extremity

Shifter

$1.7 \%$

Head

Center Stack

$1.3 \%$

Other

Torso

$1.1 \%$

Not in Frame

$0.4 \%$

Cant Tell

$0.0 \%$

$0.0 \%$

$0.0 \%$

$0.0 \%$

Armrest Front

Armrest Side

$0.1 \%$

Armrest Top

11

$0.1 \%$

Window/Beltline

6

Dri_Rt_Action_1

Null

$89.6 \%$

Phone

$6.5 \%$

Dri_Rt_Action_2

Drink

$1.3 \%$

Null

9596

$99.9 \%$

Other

$1.2 \%$

Other

$0.1 \%$

Food

$1.2 \%$

Phone

$0.0 \%$

Shifter

Drink

$0.0 \%$

Center Stack

$0.2 \%$

$0.0 \%$ 
Pas_LtForearm_1

Pas_LtElbow_1

\begin{tabular}{|c|c|c|c|c|c|}
\hline Null & 7878 & $82.0 \%$ & Null & 7878 & $82.0 \%$ \\
\hline Armrest Top & 865 & $9.0 \%$ & Touching Nothing & 797 & $8.3 \%$ \\
\hline Touching Nothing & 470 & $4.9 \%$ & Armrest Top & 355 & $3.7 \%$ \\
\hline Torso & 202 & $2.1 \%$ & Lower Extremity & 229 & $2.4 \%$ \\
\hline Armrest Side & 89 & $0.9 \%$ & Torso & 151 & $1.6 \%$ \\
\hline Cant Tell & 69 & $0.7 \%$ & Cant Tell & 82 & $0.9 \%$ \\
\hline Armrest Front & 11 & $0.1 \%$ & Not in Frame & 52 & $0.5 \%$ \\
\hline Other & 7 & $0.1 \%$ & Other & 35 & $0.4 \%$ \\
\hline Not in Frame & 7 & $0.1 \%$ & Armrest Side & 14 & $0.1 \%$ \\
\hline Lower Extremity & 5 & $0.1 \%$ & Armrest Front & 10 & $0.1 \%$ \\
\hline Pas_LtForearm_2 & & & Pas_LtElbow_2 & & \\
\hline Null & 9587 & $99.8 \%$ & Null & 9577 & $99.7 \%$ \\
\hline Torso & 12 & $0.1 \%$ & Torso & 9 & $0.1 \%$ \\
\hline Armrest Side & 2 & $0.0 \%$ & Lower Extremity & 6 & $0.1 \%$ \\
\hline Touching Nothing & 1 & $0.0 \%$ & Armrest Top & 5 & $0.1 \%$ \\
\hline \multirow[t]{2}{*}{ Armrest Top } & 1 & $0.0 \%$ & Armrest Side & 3 & $0.0 \%$ \\
\hline & & & Touching Nothing & 2 & $0.0 \%$ \\
\hline Pas_LtHand_1 & & & Armrest Front & 1 & $0.0 \%$ \\
\hline Null & 7878 & $82.0 \%$ & & & \\
\hline Not in Frame & 599 & $6.2 \%$ & Pas_LtHand_2 & & \\
\hline Lower Extremity & 507 & $5.3 \%$ & Null & 9593 & $99.9 \%$ \\
\hline Touching Nothing & 199 & $2.1 \%$ & Object Interact & 7 & $0.1 \%$ \\
\hline Cant Tell & 169 & $1.8 \%$ & Touching Nothing & 2 & $0.0 \%$ \\
\hline Object Interact & 131 & $1.4 \%$ & Lower Extremity & 1 & $0.0 \%$ \\
\hline Other & 40 & $0.4 \%$ & & & \\
\hline Head & 28 & $0.3 \%$ & Pas_LtAction_1 & & \\
\hline Torso & 19 & $0.2 \%$ & Null & 9469 & $98.6 \%$ \\
\hline Armrest Front & 11 & $0.1 \%$ & Phone & 69 & $0.7 \%$ \\
\hline Armrest Top & 10 & $0.1 \%$ & Other & 40 & $0.4 \%$ \\
\hline Armrest Side & 9 & $0.1 \%$ & Drink & 16 & $0.2 \%$ \\
\hline \multirow[t]{2}{*}{ Center Stack } & 3 & $0.0 \%$ & Food & 8 & $0.1 \%$ \\
\hline & & & Shifter & 1 & $0.0 \%$ \\
\hline
\end{tabular}




\section{NOTES TALLIES}

N_Driver_Hand_Right_ArmLt

\section{Count}

Fraction

N_Driver_Hand_Right_Cigarette

N_Driver_Hand_Right_Consol

N_Driver_Hand_Right_FloorDr

N_Driver_Hand_Right_FloorRr

N_Driver_Hand_Right_HandLt

N_Driver_Hand_Right_Lotion

N_Driver_Hand_Right_Money

N_Driver_Hand_Right_Paper

N_Driver_Hand_Right_Pen

N_Driver_Hand_Right_Ponytail

N_Driver_Hand_Right_Purse

N_Driver_Hand_Right_Sunvisor

\begin{tabular}{|c|c|c|c|}
\hline $\mathrm{N}$ & & Y & \\
\hline & 9839 & & 17 \\
\hline & $99.8 \%$ & & $0.2 \%$ \\
\hline $\mathrm{N}$ & & $\mathrm{Y}$ & \\
\hline & 9849 & & 7 \\
\hline & $99.9 \%$ & & $0.1 \%$ \\
\hline $\mathrm{N}$ & & $\mathrm{Y}$ & \\
\hline & 9852 & & 4 \\
\hline & $100.0 \%$ & & $0.0 \%$ \\
\hline $\mathrm{N}$ & & Y & \\
\hline & 9851 & & 5 \\
\hline & $99.9 \%$ & & $0.1 \%$ \\
\hline $\mathrm{N}$ & & Y & \\
\hline & 9854 & & 2 \\
\hline & $100.0 \%$ & & $0.0 \%$ \\
\hline $\mathrm{N}$ & & Y & \\
\hline & 9806 & & 50 \\
\hline & $99.5 \%$ & & $0.5 \%$ \\
\hline $\mathrm{N}$ & & Y & \\
\hline & 9855 & & 1 \\
\hline & $100.0 \%$ & & $0.0 \%$ \\
\hline $\mathrm{N}$ & & Y & \\
\hline & 9855 & & 1 \\
\hline & $100.0 \%$ & & $0.0 \%$ \\
\hline $\mathrm{N}$ & & Y & \\
\hline & 9855 & & 1 \\
\hline & $100.0 \%$ & & $0.0 \%$ \\
\hline $\mathrm{N}$ & & Y & \\
\hline & 9852 & & 4 \\
\hline & $100.0 \%$ & & $0.0 \%$ \\
\hline $\mathrm{N}$ & & $\mathrm{Y}$ & \\
\hline & 9855 & & 1 \\
\hline & $100.0 \%$ & & $0.0 \%$ \\
\hline $\mathrm{N}$ & & Y & \\
\hline & 9847 & & 9 \\
\hline & $99.9 \%$ & & $0.1 \%$ \\
\hline $\mathrm{N}$ & & Y & \\
\hline & 9854 & & 2 \\
\hline & $100.0 \%$ & & $0.0 \%$ \\
\hline
\end{tabular}


N_Driver_Hand_Right_PassengerSeat

N_Driver_Hand_Right_SeatFt

N_Driver_Hand_Right_SeatRr

N_Driver_Hand_Right_PassengerFt

N_Driver_Hand_Right_PassengerRr

N_Driver_Hand_Left_ArmRt

N_Driver_Hand_Left_Cigarette

N_Driver_Hand_Left_Door

N_Driver_Hand_Left_FloorDr

N_Driver_Hand_Left_HandRt

N_Driver_Hand_Left_Lotion

N_Driver_Hand_Left_Paper

N_Driver_Hand_Left_PassengerFt

N_Driver_Hand_Left_Ponytail
$\mathrm{N}$

9820

Y

$99.6 \%$

36

$0.4 \%$

$\mathrm{N}$

18

$99.8 \%$

$0.2 \%$

$\mathrm{N}$

$\mathrm{Y}$

9855

1

$100.0 \%$

$\mathrm{N}$

$0.0 \%$

9817

39

$99.6 \%$

$0.4 \%$

N

9854

$0.0 \%$

N

$100.0 \%$

Y

$9836 \quad 20$

$99.8 \%$

$0.2 \%$

N

Y

9810

46

$99.5 \%$

$0.5 \%$

N

9855

1

$100.0 \%$

$0.0 \%$

N

2

9854

Y

$100.0 \%$

$0.0 \%$

N

$\mathrm{Y}$

9855

1

$100.0 \%$

$0.0 \%$

N

Y

$9855 \quad 1$

$100.0 \% \quad 0.0 \%$

N

Y

$9849 \quad 7$

$99.9 \% \quad 0.1 \%$

N

Y

9853

3

$100.0 \%$

$0.0 \%$

N

9855

1

$100.0 \%$

$0.0 \%$ 
N_Driver_Hand_Left_Sunglasses

N_Driver_Hand_Left_Visor

N_Driver_Arm_Crossed_Both

N_Driver_Arm_Left_Outside

N_Driver_Arms_Both_Crossed

N_Driver_Shoulder_Holding_Phone

N_Driver_Knee_Left_Steering

N_Driver_Knee_Right_Steering

N_Passenger_Elbow_Driver_Seat

N_Passenger_Forearm_Left_ConsolOpening

N_Passenger_Hand_Left_Bag

N_Passenger_Hand_Left_Belt

N_Passenger_Hand_Left_Computer

N_Passenger_Hand_Left_Consol
$\mathrm{N}$ Y

9855

1

$100.0 \%$

$0.0 \%$

N

$\mathrm{Y}$

9855

1

$100.0 \%$

$0.0 \%$

N

Y

9855

1

$100.0 \%$

$0.0 \%$

N

Y

9811

45

$99.5 \%$

$0.5 \%$

N

Y

9855

1

$100.0 \%$

$0.0 \%$

N

Y

$9855 \quad 1$

$100.0 \%$

$0.0 \%$

N

9853

Y

$100.0 \%$

3

$0.0 \%$

N

2

9854

$0.0 \%$

N

$100.0 \%$

$\mathrm{Y}$

$9855 \quad 1$

$100.0 \%$

$0.0 \%$

N

$\mathrm{Y}$

9855

1

$100.0 \%$

$0.0 \%$

$\mathrm{N}$

$\mathrm{Y}$

$9847 \quad 9$

$99.9 \% \quad 0.1 \%$

N

Y

$9855 \quad 1$

$100.0 \% \quad 0.0 \%$

N $\quad \mathrm{Y}$

$9855 \quad 1$

$100.0 \% \quad 0.0 \%$

N

$\mathrm{Y}$

$9854 \quad 2$

$100.0 \% \quad 0.0 \%$ 
N_Passenger_Hand_Left_Console Opening

N_Passenger_Hand_Left_Driver

N_Passenger_Hand_Left_SeatDr

N_Passenger_Hand_Left_SeatRr

N_Armrest_Top_Center_Object

N_Consol_Top_Center_Cup

N_Consol_Top_Center_Object

N_Consol_Top_Center_Pet

N_Consol_Top_Center_Phone

N_Consol_Top_Center_Purse

N_Cupholder_Inside_Center_Cup

N_Cupholder_Inside_Center_Cups

N_Cupholder_Inside_Center_Food

N_Cupholder_Inside_Center_Object
$\mathrm{N}$ Y

9855

1

$100.0 \%$

$0.0 \%$

$\mathrm{N}$

$\mathrm{Y}$

9845

11

$99.9 \%$

$0.1 \%$

N

$\mathrm{Y}$

9853

3

$100.0 \%$

$\mathrm{N}$

$0.0 \%$

9855

Y

$100.0 \%$

$\mathrm{N}$

$\mathrm{T}$

9847

$99.9 \%$

$0.1 \%$

N

9852

Y

$100.0 \%$

N

9821

$99.6 \%$

35

$0.4 \%$

$\mathrm{N}$

6

9850

$99.9 \%$

$0.1 \%$

N

$\mathrm{Y}$

9838

18

$99.8 \%$

$0.2 \%$

N

$\mathrm{Y}$

$9788 \quad 68$

$99.3 \% \quad 0.7 \%$

N

Y

$8685 \quad 1171$

$88.1 \% \quad 11.9 \%$

N

9846

$99.9 \%$

$0.1 \%$

$\mathrm{N}$

9855

1

$100.0 \%$

$0.0 \%$

$\mathrm{N}$

9628
$97.7 \%$

$2.3 \%$ 
N_Cupholder_Inside_Center_Phone

N_Cupholder_Inside_Center_Purse

N_Cupholder_Inside_Center_Sunglasses

N_Driver_Eyes_Down_Consol

N_Driver_Consol_Remove_Sunglasses

N_Driver_Head_Remove_Sunglasses

N_Driver_Head_Top_Sunglasses

N_Driver_Mouth_Center_Sunglasses

N_Driver_Lap_Center_Object

N_Driver_Lap_Center_Pet

N_Driver_Lap_Center_Phone

N_Driver_Lap_Center_Purse

N_Driver_Lap_Right_Purse

N_Passenger_Lap_Center_Bag
$\mathrm{N}$

9798

Y

$99.4 \%$

58

$\mathrm{N}$

$0.6 \%$

$\mathrm{Y}$

9851

5

$99.9 \%$

$0.1 \%$

N

$\mathrm{Y}$

9846

10

$99.9 \%$

$0.1 \%$

$\mathrm{N}$

$\mathrm{Y}$

9855

1

$100.0 \%$

$0.0 \%$

N

Y

9855

1

$100.0 \%$

N

9854

$0.0 \%$

Y

$100.0 \%$

2

$0.0 \%$

N

9846

10

$99.9 \%$

$0.1 \%$

N

1

9855

$0.0 \%$

N

$100.0 \%$

$\mathrm{Y}$

9843

13

$99.9 \%$

$0.1 \%$

N

$\mathrm{Y}$

9855

1

$100.0 \%$

$0.0 \%$

N

Y

$9687 \quad 169$

$98.3 \% \quad 1.7 \%$

N

Y

9782

74

$99.2 \%$

$0.8 \%$

N

3

9853

$0.0 \%$

N

$100.0 \%$

9

9847

$0.1 \%$ 
N_Passenger_Lap_Center_Pet

N_Passenger_Lap_Center_Purse

N_Passenger_Seat_Center_Pet

N_Driver_Belt_Don_Driving

N_Driver_Belt_Don_Stopped

N_Driver_Belt_Not_Used

N_Driver_Belt_On_Adjusted

N_Driver_Body_All_Outside

N_Driver_Car_Not_Moving

N_Driver_Steering_No_Contact
$\mathrm{N}$

9851

$99.9 \%$

5

$\mathrm{N}$

$0.1 \%$

9847

9

$99.9 \%$

$0.1 \%$

$\mathrm{N}$

$\mathrm{Y}$

9839

17

$99.8 \%$

$0.2 \%$

N

Y

9855

1

$100.0 \%$

N

9854

$0.0 \%$

Y

$100.0 \%$

N

9854

Y

$100.0 \%$

$\mathrm{N}$

9853

$0.0 \%$

$100.0 \%$

3

$\mathrm{N}$

$$
9791
$$

65

$99.3 \%$

$0.7 \%$

N

$8701 \quad 1155$

$88.3 \%$

$11.7 \%$

N

$\mathrm{Y}$

9801

55

$99.4 \%$

$0.6 \%$ 